\title{
AN ON-LINE SUPPLEMENT TO: A BAYESIAN SPATIOTEMPORAL MODEL FOR RECONSTRUCTING CLIMATE FROM MULTIPLE POLLEN RECORDS
}

\author{
By Lasse Holmström*, Lissa Ilvonen*, Heikki Sepp ${ }^{\dagger}$, And SiIm \\ $\mathrm{VESKI}^{\ddagger}$, \\ University of Oulu*, University of Helsinki ${ }^{\dagger}$ and Tallinn University of \\ Technology
}

1. Analysis of the taxon response model. We consider here whether the Gaussian taxon response model described in Section 2.3 of the main paper leads to a reasonable description of how the observed relative abundance of a taxon depends on temperature. We also discuss the extent to which $\beta_{j}$ can be interpreted as an optimal taxon temperature and what role the tolerance parameter $\gamma_{j}$ plays in this.

Consider a taxon $j$ and temperature $x$ (either modern or past). In a slightly simplified notation, let

$$
\lambda_{j}(x)=\alpha_{j} \exp \left[-\left(\frac{\beta_{j}-x}{\gamma_{j}}\right)^{2}\right], j=1, \ldots, l,
$$

be the Gaussian response function and let $y_{j} \in[0,100]$ be the observed relative abundance of taxon $j$. Here the parameters $\alpha_{j}, \beta_{j}$ and $\gamma_{j}$ are thought of as fixed. According to our multinomial likelihood model $((7)$ in the main paper) $y_{j}$ has a binomial distribution given the taxon specific probability $p_{j}(x)$ which determines the probability that an observed pollen grain belongs to taxon $j$. The probability $p_{j}(x)$ is itself a component of a Dirichlet random vector whose distribution is determined by the parameters $\lambda_{1}, \ldots, \lambda_{l}$ so that, by the properties of the Dirichlet distribution,

$$
\mathbb{E} p_{j}(x)=\frac{\lambda_{j}(x)}{\sum_{k=1}^{l} \lambda_{k}(x)} .
$$

It follows that

$$
\mathbb{E}\left(y_{j} \mid x\right)=\mathbb{E}\left(\mathbb{E}\left(y_{j} \mid p_{j}(x)\right)=\mathbb{E}\left(100 p_{j}(x)\right)=100 \frac{\lambda_{j}(x)}{\sum_{k=1}^{l} \lambda_{k}(x)} .\right.
$$

A non-parametric estimate of the regression function $\mathbb{E}\left(y_{j} \mid x\right)$ can then be obtained from the training set and one can investigate how well it conforms to the parametric model (S.3). 
Thus, let $\left[x_{i}, y_{i j}\right], i=1, \ldots, n$ be the training data where $y_{i j}$ is the observed relative abundance of taxon $j$ at site $i$ with temperature $x_{i}$. Let $\hat{f}_{j}(x)$ be a non-parametric fit to these data, so that

$$
\mathbb{E}\left(y_{j} \mid x\right) \approx \hat{f}_{j}(x)
$$

We check the plausibility of the Gaussian response assumption by investigating how well the approximation

$$
\hat{f}_{j}(x) \approx 100 \frac{\lambda_{j}(x)}{\sum_{k=1}^{l} \lambda_{k}(x)} .
$$

appears to hold for the most important taxa in our data. To check (S.4), posterior mean values are used for the parameters $\alpha_{j}, \beta_{j}$ and $\gamma_{j}$ in the right hand side expression although this choice is probably suboptimal when the goal is to make the approximation (S.4) as accurate as possible. In the following we refer to the right side of (S.4) as the "Gaussian response curve" although because of the denominator it in general does not have to resemble the standard Gaussian function but can in fact assume much more general shapes. A standard Gaussian shape can be produced when the denominator $\sum_{k=1}^{l} \lambda_{k}(x)$ is approximately constant. This may be the case for example when the scaling parameters $\alpha_{j}$ are approximately equal and the optimal temperatures $\beta_{j}$ are uniformly distributed.

The results for the ten most abundant taxa in the combined set of training and core data are shown in Figures S.1 and S.2. Together they account for over $96 \%$ of all relative abundances. Note that for clarity of presentation the vertical scales in the panels of these and the subsequent figures are different. In Figure S.1 the response curves are displayed on the training set temperature range $\left[-4.7^{\circ} \mathrm{C}, 7.1^{\circ} \mathrm{C}\right]$. The non-parametric fit employed is robust Loess smoothing (Cleveland, 1979). The fits in most cases look rather similar to the curves defined by the Gaussian response curves suggesting that our relative abundance model is plausible. In many cases the distribution of the training data appears to match the left tail of the response curve. This is confirmed by Figure S.2 that shows the response curves for a much larger range of temperatures. For most taxa the optimal temperature ranges suggested by these curves do not seem unreasonable. The response curves for the lakes Raigastvere and Rõuge look similar which is natural because of their close proximity in Estonia. On the other hand, the geographical locations of lakes Arapisto and Flarken are different and their responses also often look different from those of the two Estonian lakes (cf. Figure 5 in the main paper). The response curves of the two multi-core models (SI and 
SP) look similar which is consistent with the fact that the corresponding temperature reconstructions also are similar.

The Betula (birch) response is nearly linear over a large range of temperatures showing no pronounced maximum within a reasonable temperature interval (Figure S.2). We also note that the non-parametric fit to the training data (Figure S.1) hints at bimodality which is probably due to the presence of both extreme northern and more southern tree types within the same taxon. For Alnus (alder), Corylus (hazel), Quercus (oak), Ulmus (elm) and Tilia (linden) the optimal temperature (highest taxon probability) suggested by the response curves is clearly above the training set range (Figure S.2). This is not surprising as the training lakes are located in the northern part of their natural ranges. For most reconstructions the maximum relative abundances (determined by the relative sizes of the posterior means of the $\alpha_{j} \mathrm{~s}$ if the denominator of (S.2) is approximately constant) of these taxa achieved at optimal temperatures are predicted to reach levels well above their share in the training set and core data. However, the estimated maximum taxon probabilities of these five taxa for the lake Arapisto reconstruction are generally lower than for the other three lakes which all are more southern. Again, this is not unexpected considering the modest share of most of these taxa in the Arapisto core (Figure S.13). The optimal temperatures for Pinus (pine) and Picea (spruce) are reasonably well captured by the optimum observed abundances in the training set. Gramineae (grasses) are widespread in areas of boreal and temperate climate and their natural habitat cover the entire Fennoscandia. The various reconstruction models put its optimal temperature between $2^{\circ} \mathrm{C}$ and $5^{\circ} \mathrm{C}$ but the training set (Figure S.1) appears to include warmer sites where Gramineae pollen was observed in greater relative abundance than the overall relative share of this taxon in all data $(2 \%)$. The abundance of Carex-type (sedges) is known to be more related to ecology (mostly open, moist growing sites) than climate. This may explain the rather unstructured response curves that vary greatly between the different lakes.

The posterior distributions of the taxon optimal temperature parameter $\beta_{j}$ and the tolerance $\gamma_{j}$ are shown in Figures S.3 and S.4. We first note how for the warmer temperature taxa (Alnus, Corylus, Quercus, Ulmus and Tilia) the posterior $\beta_{j}$ 's are much higher than their prior values (the red curve). This may be explained by the fact that the prior distribution for $\beta_{j}$, although very wide, is still centered on the optimal value estimated from the training set and the training lake temperatures (mean value $2.6^{\circ} \mathrm{C}$ ) are likely to be considerably lower than many of the past temperatures at the core lakes. 
The posterior distributions of the optimal temperature parameter generally differ between the six reconstructions but for a taxon with a well-defined maximum in the Gaussian response curve, the order from lower to higher temperatures in which the optimal values for various reconstructions appear are generally similar in Figures S.2 and S.3. In such cases the optimum suggested by the response curve and the posterior mean of $\beta_{j}$ can also be similar, except when the response curve maximum falls at a very high temperature. Note that in such cases (Corylus, Quercus and Tilia) the response curve maximum and the posterior mean of $\beta_{j}$ still tend to be similar for the multi-core reconstructions (SI and SP) suggesting one potential benefit of these more complex models if a clearly interpretable role for $\beta_{j}$ is desired.

It appears from the above discussion that there is at best only a rough correspondence between the taxon optimal temperature parameter $\beta_{j}$ and the optimal temperature suggested by the model, i.e., the temperature at which the response curve (S.3) and consequently the expected taxon relative abundance reaches its highest value. Of course, part of this lack of correspondence can be explained by the fact that the response curves in Figure S.2 in a sense are only particular point estimates of the probability $p_{j}(x)$ which in our model is in a fact a stochastic process and therefore they should not be considered as accurate representations of actual taxon occurrence probabilities. Still, we believe that the above observations make it quite clear that one should not interpret the parameter $\beta_{j}$ as representing a precise optimal taxon temperature. This in fact is a direct consequence of how the temperature response model is designed. The Gaussian functions (S.1) and the associated $\beta_{j}$ 's are just building blocks of the full relative response model in (S.2) and (S.3) that can assume many other shapes besides a unimodal function centered at $\beta_{j}$. Further, according to Figure S.4, the posterior values of the tolerance parameter $\gamma_{j}$ tend to be very large which makes the response function $\lambda_{j}(x)$ in (S.1) flat and therefore $\beta_{j}$ 's role as a clear well-defined optimum temperature not very convincing. For example, note how the very large values of $\gamma_{j}$ for Betula and Flarken's Pinus make the corresponding response curves in Figure S.2 useless for finding an optimal temperature.

2. Reference records from Greenland and Scandinavia. The NGRIP Greenland ice core oxygen isotopic profile in Figure S.5 is often used as a reference when Holocene climate is reconstructed for Northern Europe and the North Atlantic region (Andersen et al., 2004). According to this profile, instead of a relatively short time span of a couple of hundred years as suggested by Figure 6 of the main paper, the transition to warmer Holocene 
climate has been considerably more gradual. The spatially independent and spatio-temporal reconstructions (Figures 7 and 8) appear to be in better agreement with such a climate history. Similar conclusions can be drawn from Figure S.6 that displays the temperature derived from the Agassiz and Renland ice core records as deviations from the smoothed estimate of present temperature in Greenland (M.Vinther et al., 2009). Further evidence for the gradual onset of warming is provided by the oxygen isotopic profile from Lake Igelsjön located ca. $10 \mathrm{~km}$ south of Lake Flarken displayed in Figure S.7 (Hammarlund et al., 2003) and the chironomid-based temperature reconstructions from Norway in Figures S.8 and S.9 (Velle et al., 2005).

3. Alternative reconstructions. The chronology of Lake Rõuge is relatively sparse from 10200 to $9400 \mathrm{BP}$ consisting of dates that are 200 years apart. This may add to the uncertainty in the timing of the onset of early Holocene warming in temperature reconstruction from Lake Rõuge core. We therefore considered also reconstructions where all data for Lake Rõuge before $9400 \mathrm{BP}$ were left out. The reconstruction made independently for Rõuge is shown in Figure S.10 and the spatially independent and spatiotemporal joint reconstructions for all four lakes are shown in Figures S.11 and S.12. In comparison with Figures 7 and 8 of the main paper the reconstructions for Arapisto, Flarken and Raigastvere have not changed much. The most notable difference is the somewhat shaper onset of early Holocene warming especially in the spatio-temporal reconstructions. This is to be expected now that the beginning of warming for all three lakes is almost simultaneous and therefore spatial correlation smooths the differences less. Of course, the confidence intervals for Rõuge increase now rapidly prior to $9400 \mathrm{BP}$ as the reconstruction there is based purely on prior assumptions.

4. The core chronologies. Towards the end of this document are listed the core chronologies from the four lakes used for temperature reconstruction, as well as their union chronology used for spatio-temporal reconstruction. The dates are expressed as years before present, where 'present' is set at AD 1950. A cross marks a union chronology date for which pollen taxon abundances are not available. Thus, for example in the case of Lake Arapisto, the three top-most sediment samples are dated at 0,278 and 553 years before present, respectively, and so on.

5. Pollen abundances in sediment layers. Figure S.13 after the chronologies displays for each core lake the relative abundances of the ten most common pollen types in the sediment samples. The black silhouette shows the percentage value of each taxon and the yellow silhouette is the 
percentage multiplied by 10 , which helps visualize the development of the lowest abundances. 

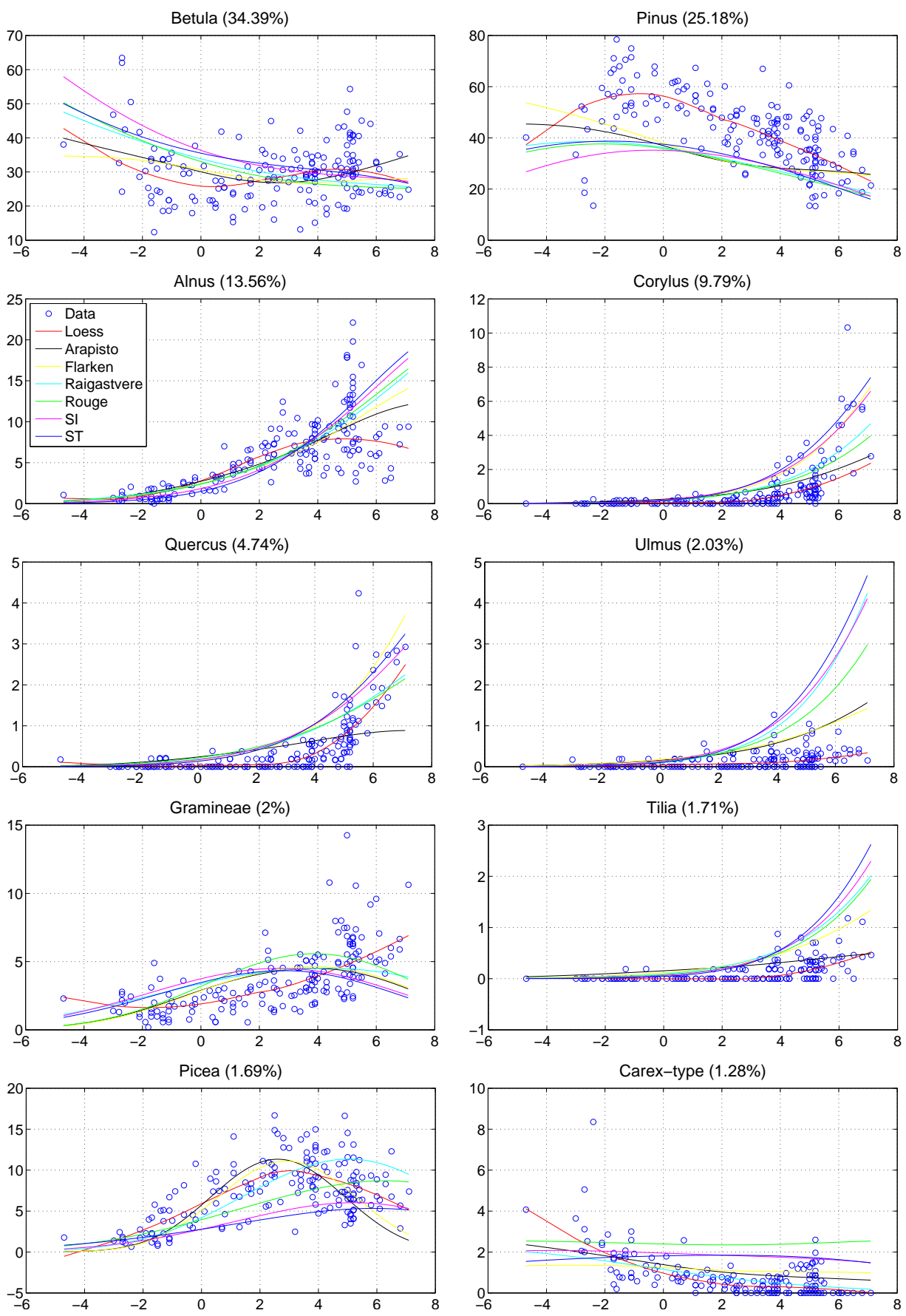

FiguRE S.1. Checking the plausibility of the Gaussian response model for the ten most abundant taxa. The share of a taxon in all pollen data is shown in the panel title. The legend which is shown only in one instance holds for all panels. The training data are shown as little circles and a non-parametric smooth fitted to them (left side of (S.4)) is shown in red. The other curves correspond to the right side of (S.4) for the various reconstructions: independent reconstruction for each lake, the spatially independent model (SI), and the spatio-temporal model (ST). Horizontal axis is the annual mean temperature $\left({ }^{C} \mathrm{C}\right)$. 

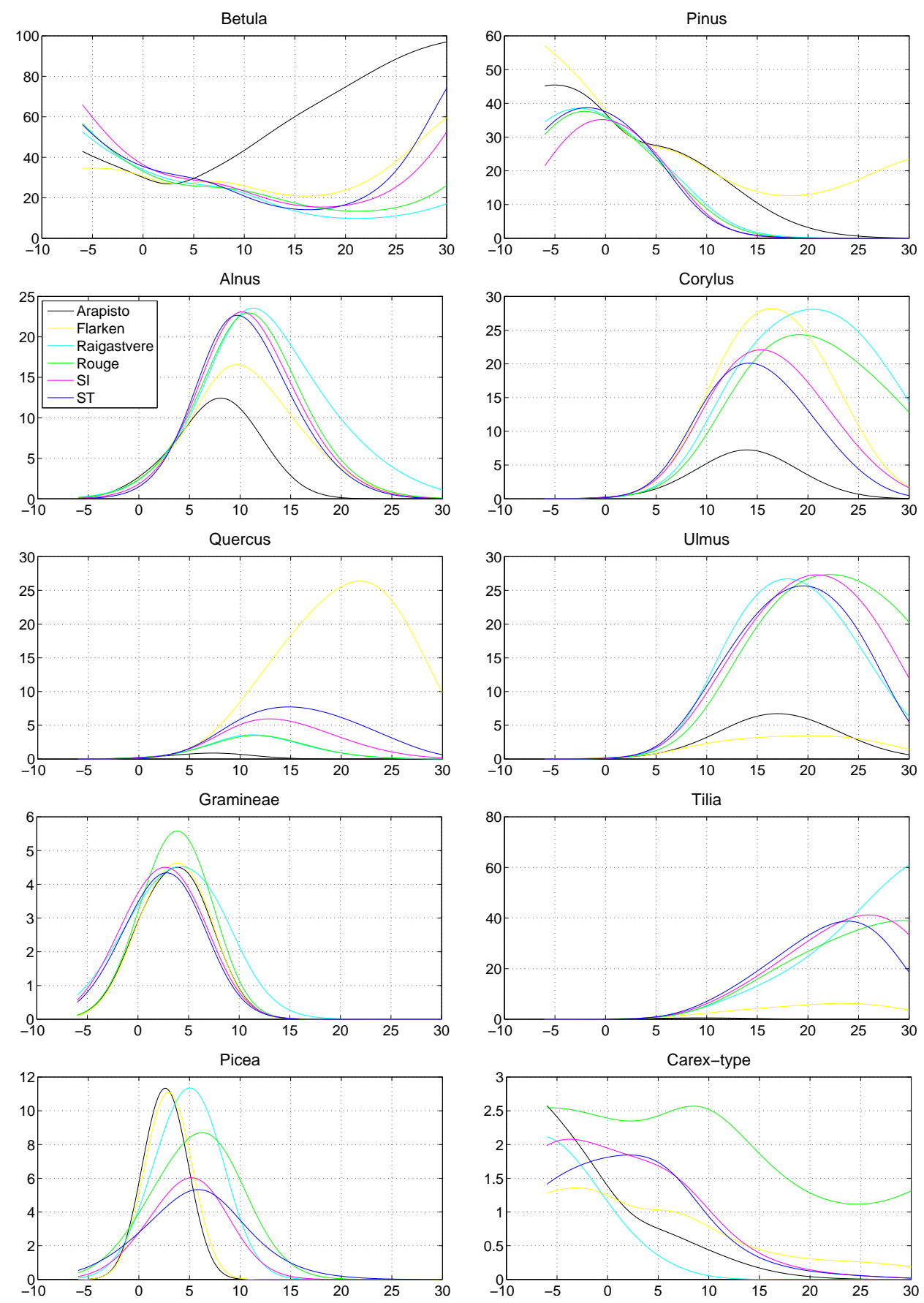

Figure S.2. The Gaussian response model curves of Figure S.1 extended to a wider temperature range. 

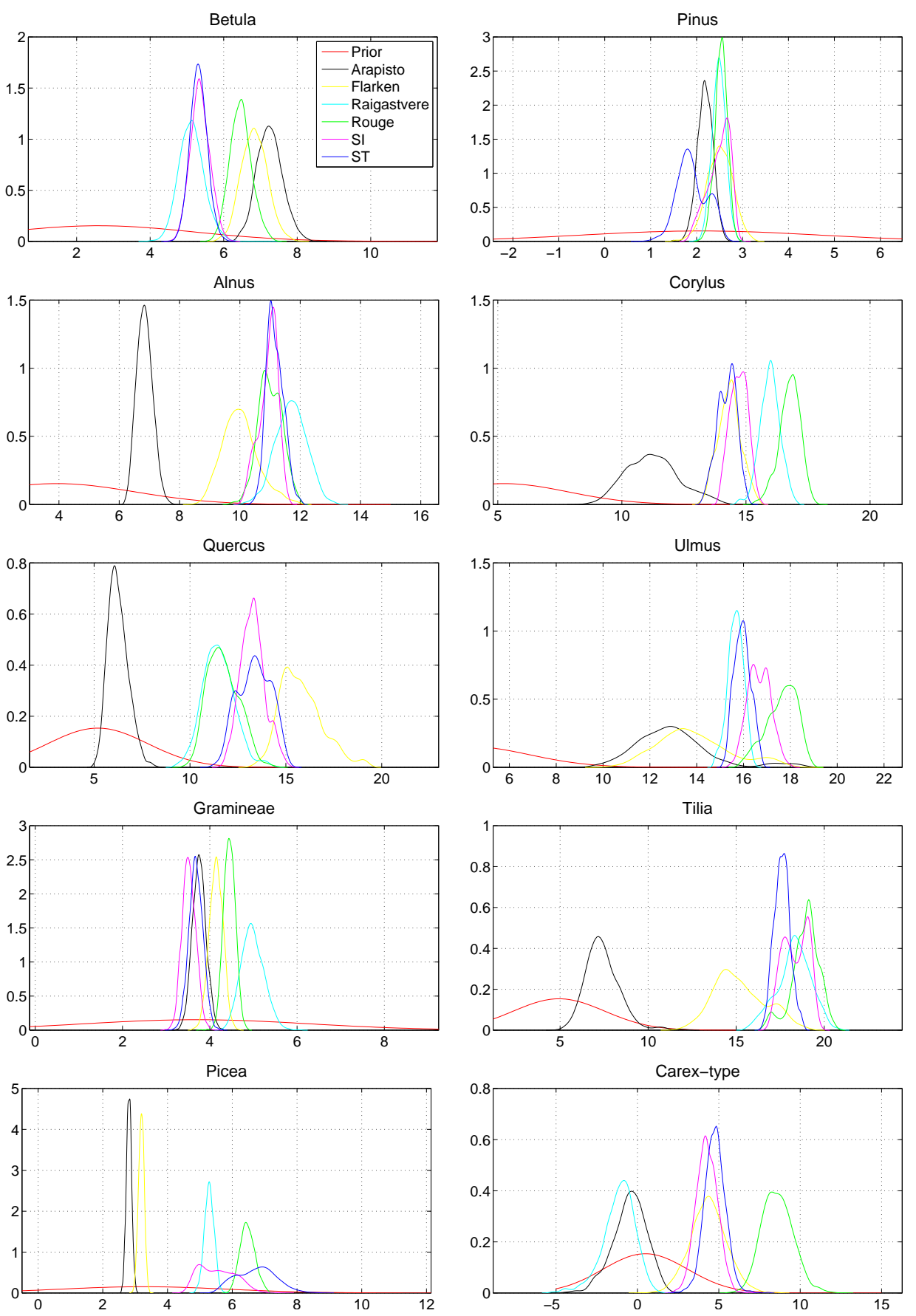

FiguRE S.3. The posterior distributions of the optimal temperature parameter $\beta_{j}$ for the ten most abundant taxa. The colors used for different reconstruction models are indicated in the legend. The prior distribution of $\beta_{j}$ (red) is different for each taxon and shows only partially in most panels because each panel focuses on the temperature range where the supports of the posterior distributions are located. 

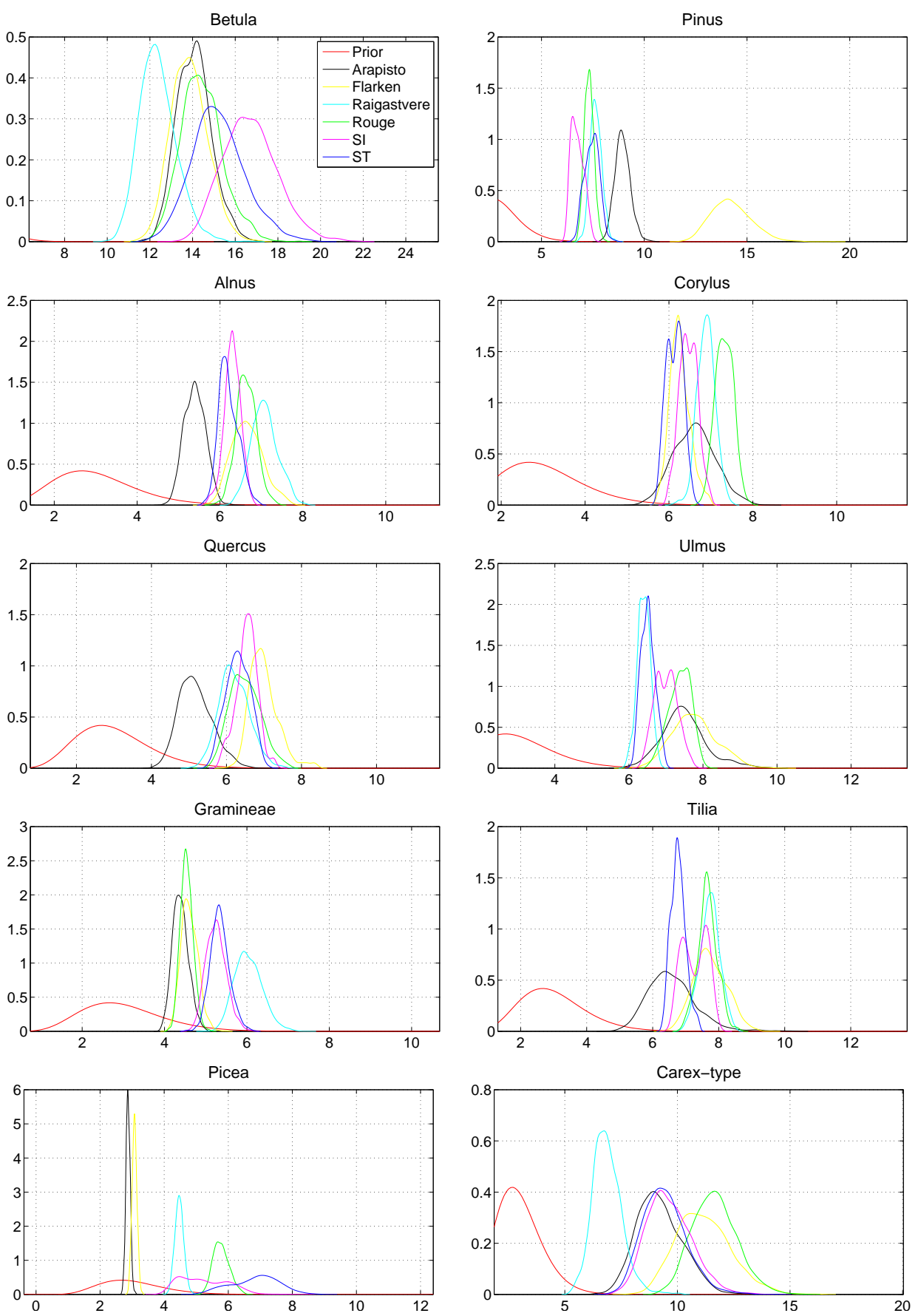

FIGURE S.4. The posterior distributions of the tolerance parameter $\gamma_{j}$ for the ten most abundant taxa. The colors used for different reconstruction models is indicated in the legend. The prior distribution of $\gamma_{j}$ (red) is the same for taxa but shows only partially in most panels because each panel focuses on the temperature range where the supports of the posterior distributions are located. 


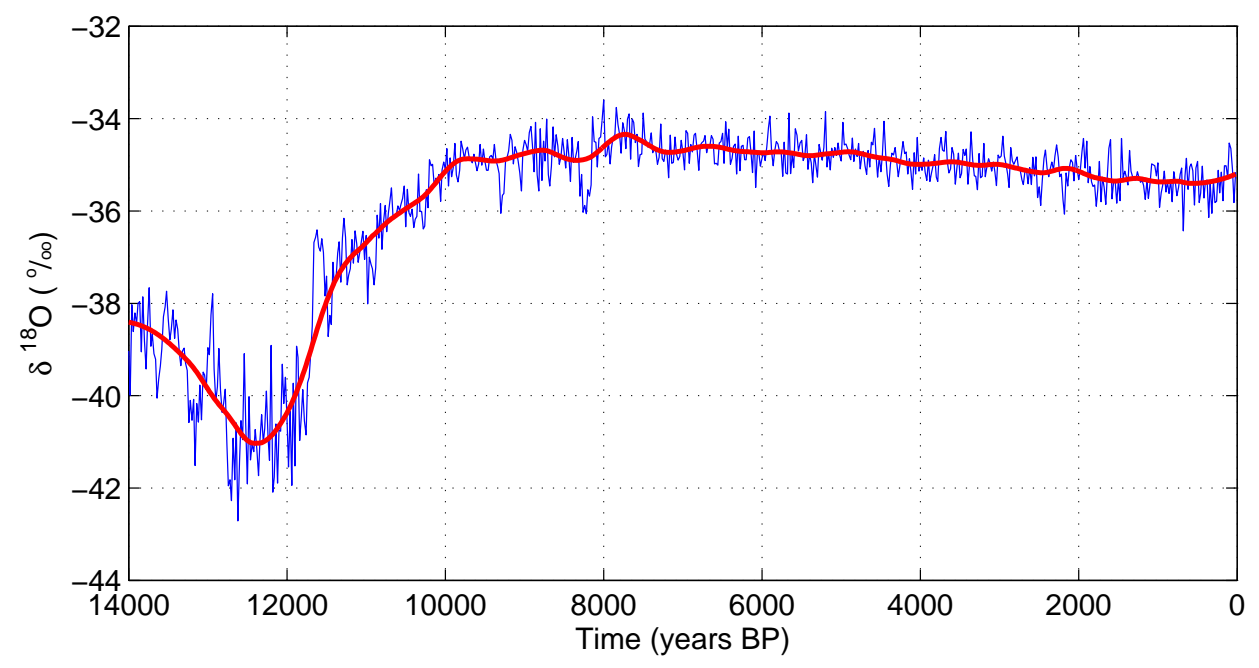

Figure S.5. The Greenland NGRIP oxygen isotopic profile for the last 14000 years. Isotopic values $\left(\delta^{18} O\right)$ are expressed in permil with respect to Vienna Standard Mean Ocean Water (V-SMOW). The red curve is a robust loess smooth.

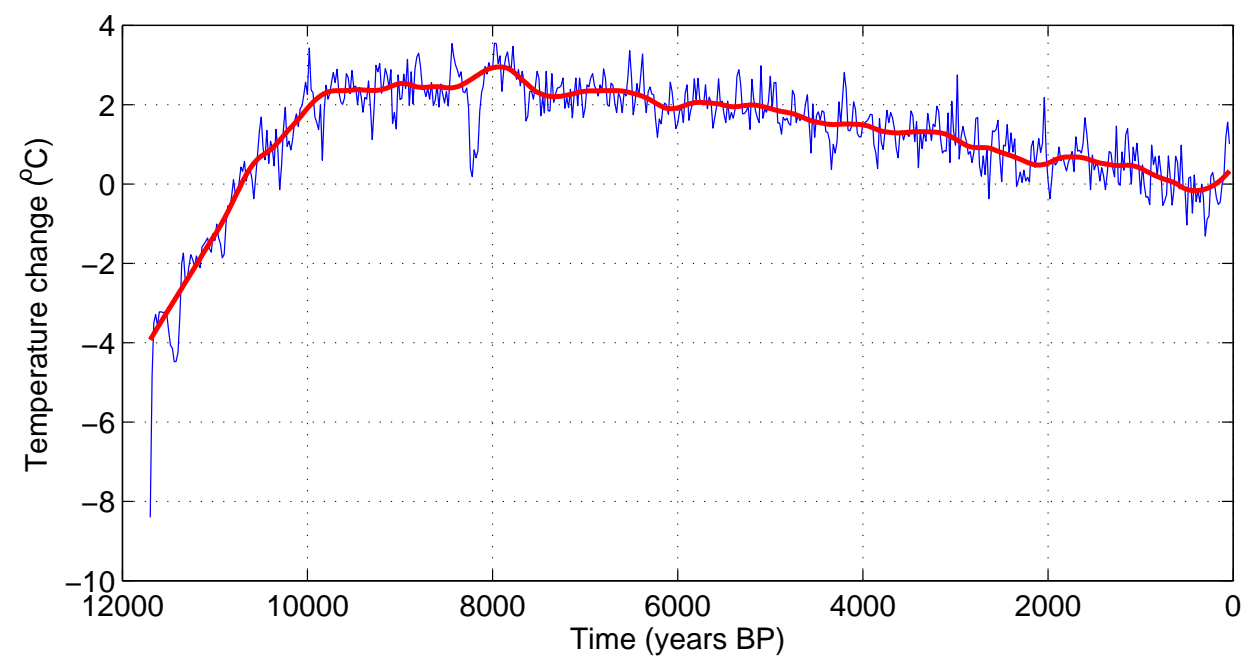

FIGURE S.6. The temperature for the last 11700 years derived from the Greenland Agassiz and Renland ice core records. The temperature is given as deviations from the smoothed estimate of present temperatures in Greenland. The red curve is a robust loess smooth. 


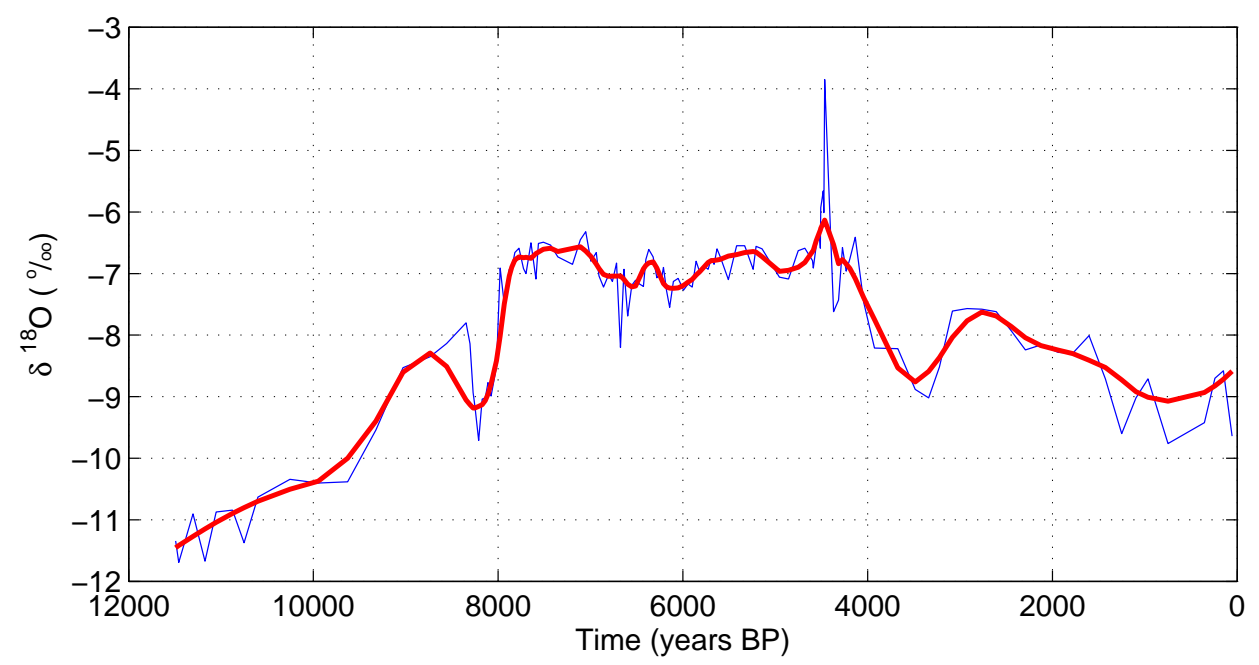

Figure S.7. An oxygen isotopic profile from Lake Igelsjön in south central Sweden (Hammarlund et al., 2003). Isotopic values $\left(\delta^{18} O\right)$ are expressed in permil with respect to the Vienna Pee Dee Belemnite (V-PDB) standard. The red curve is a robust loess smooth.

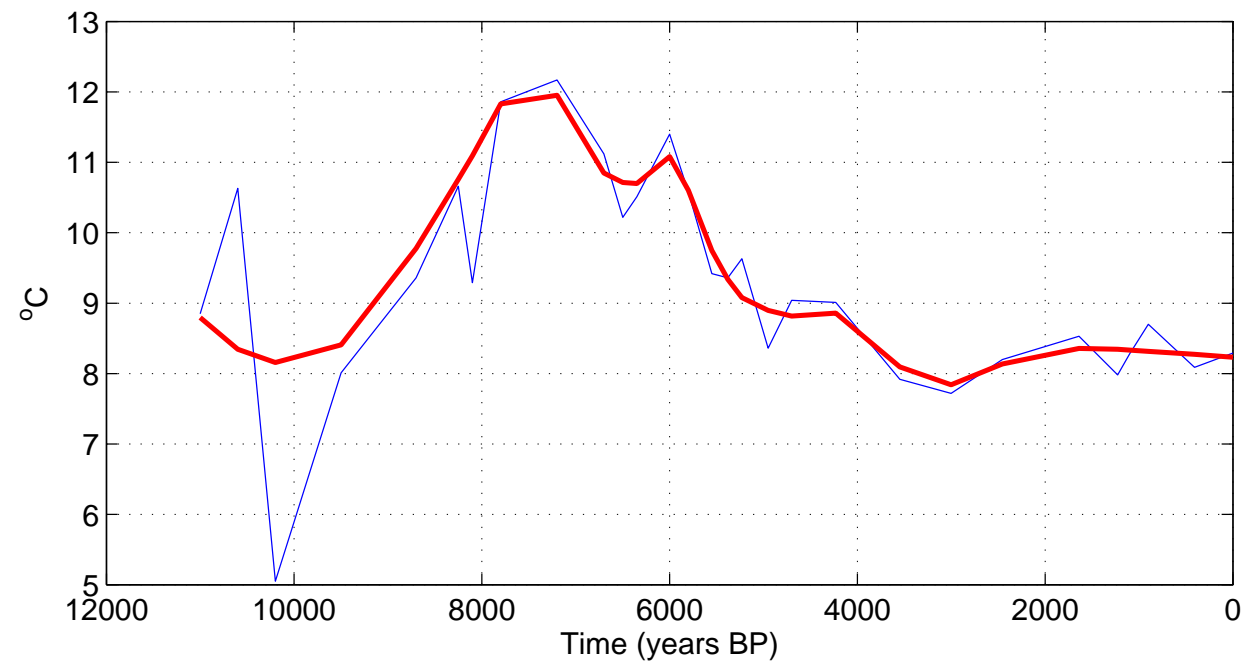

FiguRE S.8. A chironomid-based temperature reconstruction from Lake Finse Stasjonsdam in mid-southern Norway for the last 11000 years (Velle et al., 2005). The red curve is a robust loess smooth. 


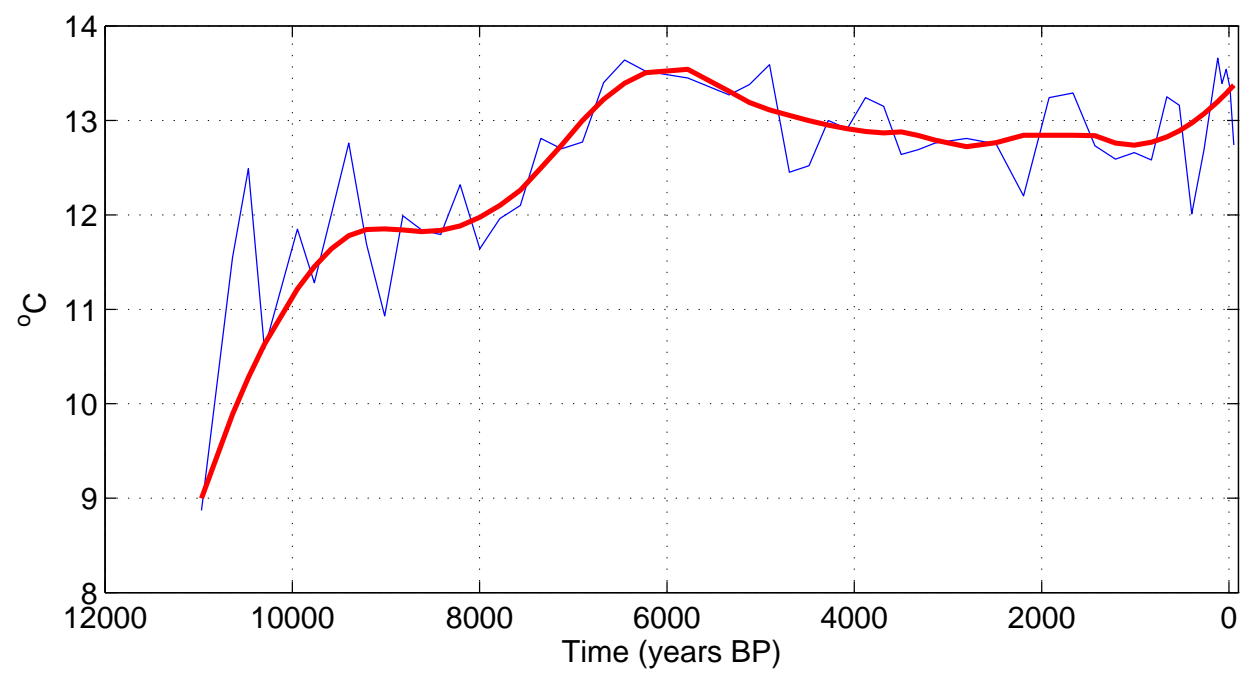

FiguRE S.9. A chironomid-based temperature reconstruction from Lake Vestre Øykjamyrtjørn in southwestern Norway for the last 11000 years (Velle et al., 2005). The red curve is a robust loess smooth.

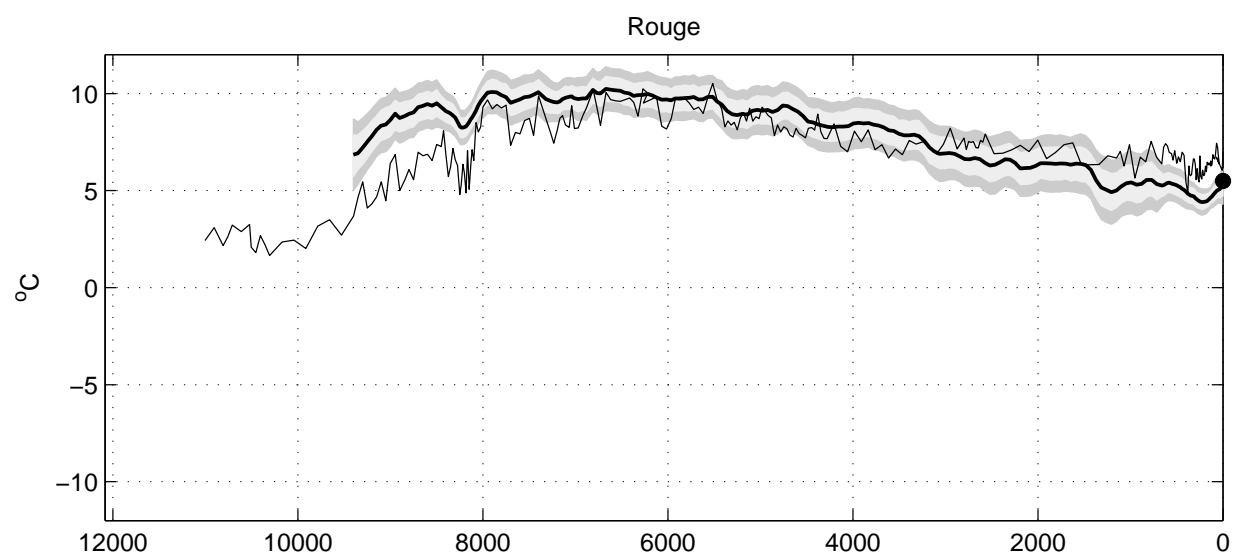

FIgURE S.10. The temperature reconstruction for Lake Rõuge when all data before 9400 $B P$ have been left out. Light and dark gray show the point-wise and simultaneous 95\% credible bands, respectively. Horizontal axis: time in years before present. Vertical axis: mean annual temperature in centigrades. The dot at AD 1950 marks the current mean annual instrumental temperature. 

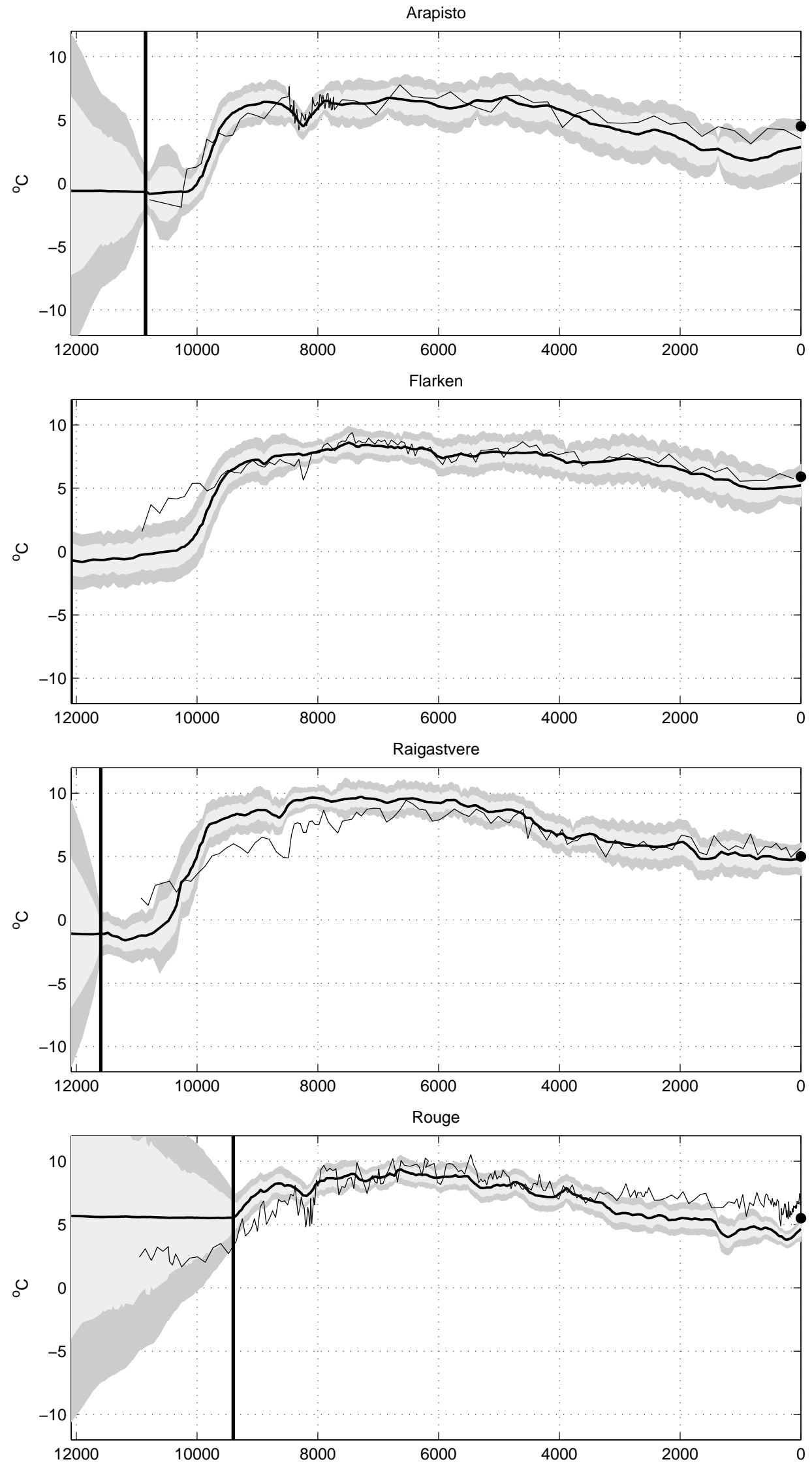

FIGURE S.11. Temperature reconstructions based on the spatially independent model with no explicit spatial interaction when all data for Lake Rõuge before 9400 BP have been left out. Light and dark gray show the point-wise and simultaneous $95 \%$ credible bands, respectively. For each lake, the black line marks the oldest date in its own chronology. Horizontal axis: time in years before present. Vertical axis: mean annual temperature in centigrades. The dot at AD 1950 marks the current mean annual instrumental temperature. 

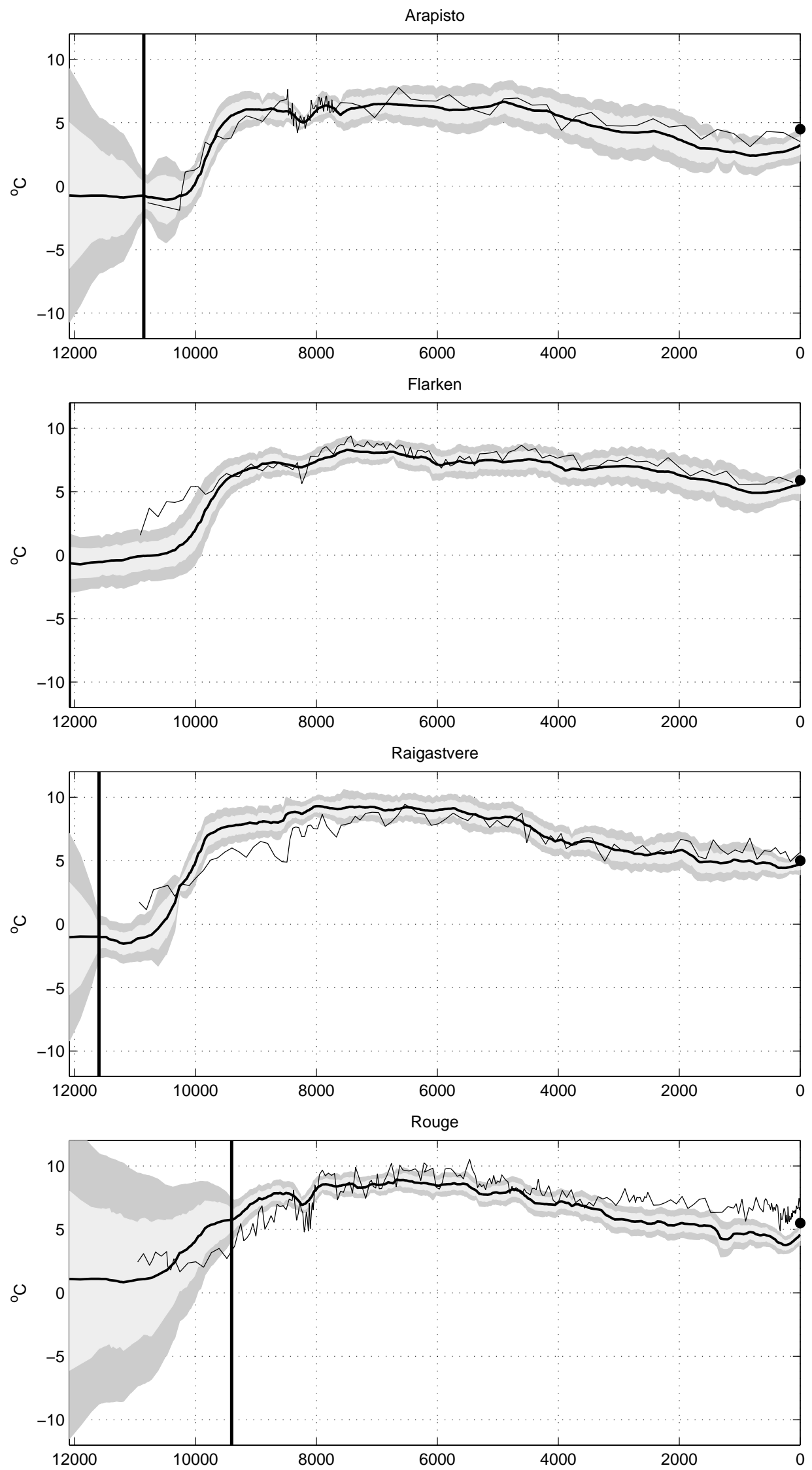

FIGURE S.12. Temperature reconstructions based on the full spatio-temporal model when all data for Lake Rõuge before 9400 BP have been left out. Light and dark gray show the point-wise and simultaneous 95\% credible bands, respectively. For each lake, the black line marks the oldest date in its own chronology. Horizontal axis: time in years before present. Vertical axis: mean annual temperature in centigrades. The dot at AD 1950 marks the current mean annual instrumental temperature. 


\section{References.}

Andersen, K. K. et al. (2004). High-resolution record of Northern Hemisphere climate extending into the last interglacial period. Nature 431 147-151.

Cleveland, W. S. (1979). Robust Locally Weighted Regression and Smoothing Scatterplots. Journal of the American Statistical Association 74 829-836.

Hammarlund, D., Buø"rck, S., Buchardt, B., Israelson, C. and Thomsen, C. T. (2003). Rapid hydrological changes during the Holocene revealed by stable isotope records of lacustrine carbonates from Lake Igelsjön, southern Sweden. Quaternary Science Reviews 22353 - 370.

Vinther, B. M. et al. (2009). Holocene thinning of the Greenland ice sheet. Nature 461 $385-388$.

Velle, G., Brooks, S. J., Birks, H. J. B. and Willassen, E. (2005). Chironomids as a tool for inferring Holocene climate: an assessment based on six sites in southern Scandinavia. Quaternary Science Reviews 241429 - 1462. 


\begin{tabular}{|c|c|c|c|c|}
\hline Union & Arapisto & Flarken & $\begin{array}{c}\text { Raigast- } \\
\text { vere }\end{array}$ & Rouge \\
\hline 0 & 0 & $x$ & 0 & 0 \\
\hline 9 & $x$ & $x$ & $x$ & 9 \\
\hline 29 & $x$ & $x$ & $x$ & 29 \\
\hline 41 & $x$ & $x$ & $x$ & 41 \\
\hline 50 & $x$ & $x$ & $x$ & 50 \\
\hline 59 & $x$ & $x$ & $x$ & 59 \\
\hline 70 & $x$ & $x$ & $x$ & 70 \\
\hline 80 & $x$ & $x$ & $x$ & 80 \\
\hline 86 & $x$ & $x$ & 86 & $x$ \\
\hline 89 & $x$ & $x$ & $x$ & 89 \\
\hline 100 & $x$ & $x$ & $x$ & 100 \\
\hline 111 & $x$ & $\mathrm{x}$ & $x$ & 111 \\
\hline 118 & $x$ & 118 & $x$ & $\mathrm{x}$ \\
\hline 120 & $x$ & $x$ & $x$ & 120 \\
\hline 129 & $x$ & $x$ & $x$ & 129 \\
\hline 133 & $x$ & $x$ & $x$ & 133 \\
\hline 136 & $x$ & $x$ & $x$ & 136 \\
\hline 150 & $x$ & $x$ & $x$ & 150 \\
\hline 160 & $x$ & $x$ & $x$ & 160 \\
\hline 170 & $x$ & $x$ & $\mathrm{x}$ & 170 \\
\hline 172 & $x$ & $x$ & 172 & $\mathrm{x}$ \\
\hline 180 & $x$ & $x$ & $\mathrm{x}$ & 180 \\
\hline 190 & $x$ & $x$ & $x$ & 190 \\
\hline 200 & $x$ & $x$ & $x$ & 200 \\
\hline 210 & $x$ & $x$ & $x$ & 210 \\
\hline 220 & $x$ & $x$ & $x$ & 220 \\
\hline 230 & $x$ & $x$ & $x$ & 230 \\
\hline 240 & $x$ & $x$ & $x$ & 240 \\
\hline 251 & $x$ & $x$ & $x$ & 251 \\
\hline 259 & $x$ & $x$ & 259 & 259 \\
\hline 270 & $\mathrm{x}$ & $x$ & $x$ & 270 \\
\hline 278 & 278 & $x$ & $x$ & $\mathrm{x}$ \\
\hline 280 & $x$ & $x$ & $x$ & 280 \\
\hline 291 & $x$ & $x$ & $x$ & 291 \\
\hline 300 & $x$ & $x$ & $x$ & 300 \\
\hline 311 & $x$ & $x$ & $x$ & 311 \\
\hline 320 & $x$ & $x$ & $x$ & 320 \\
\hline 331 & $x$ & $x$ & $x$ & 331 \\
\hline 341 & $x$ & $x$ & $\mathrm{x}$ & 341 \\
\hline 345 & $x$ & $x$ & 345 & $x$ \\
\hline 350 & $x$ & 350 & $\mathrm{x}$ & $\mathrm{x}$ \\
\hline 352 & $x$ & $\mathrm{x}$ & $x$ & 352 \\
\hline
\end{tabular}

\begin{tabular}{|c|c|c|c|c|}
\hline Union & Arapisto & Flarken & $\begin{array}{c}\text { Raigast- } \\
\text { vere }\end{array}$ & Rouge \\
\hline 361 & $\mathrm{x}$ & $x$ & $x$ & 361 \\
\hline 370 & $x$ & $x$ & $x$ & 370 \\
\hline 380 & $x$ & $x$ & $x$ & 380 \\
\hline 400 & $x$ & $x$ & $x$ & 400 \\
\hline 421 & $x$ & $x$ & $x$ & 421 \\
\hline 431 & $x$ & $x$ & 431 & $x$ \\
\hline 442 & $x$ & $x$ & $x$ & 442 \\
\hline 461 & $x$ & $x$ & $x$ & 461 \\
\hline 483 & $x$ & $x$ & $x$ & 483 \\
\hline 500 & $x$ & $x$ & $x$ & 500 \\
\hline 517 & $x$ & $x$ & 517 & $x$ \\
\hline 522 & $x$ & $x$ & $\mathrm{x}$ & 522 \\
\hline 540 & $x$ & $x$ & $x$ & 540 \\
\hline 553 & 553 & $x$ & $x$ & $x$ \\
\hline 557 & $\mathrm{x}$ & $x$ & $x$ & 557 \\
\hline 576 & $x$ & 576 & $x$ & $x$ \\
\hline 582 & $x$ & $x$ & $x$ & 582 \\
\hline 602 & $x$ & $x$ & $x$ & 602 \\
\hline 618 & $x$ & $x$ & 618 & $x$ \\
\hline 621 & $x$ & $x$ & $x$ & 621 \\
\hline 641 & $x$ & $x$ & $x$ & 641 \\
\hline 661 & $x$ & $x$ & $x$ & 661 \\
\hline 716 & $x$ & $x$ & $x$ & 716 \\
\hline 734 & $x$ & $x$ & 734 & $\mathrm{x}$ \\
\hline 770 & $x$ & $x$ & $x$ & 770 \\
\hline 796 & $x$ & 796 & $x$ & $x$ \\
\hline 825 & $x$ & $\mathrm{x}$ & $x$ & 825 \\
\hline 828 & 828 & $x$ & $x$ & $x$ \\
\hline 850 & $x$ & $x$ & 850 & $x$ \\
\hline 880 & $x$ & $x$ & $x$ & 880 \\
\hline 934 & $x$ & $x$ & $x$ & 934 \\
\hline 966 & $x$ & $x$ & 966 & $x$ \\
\hline 989 & $x$ & $\mathrm{x}$ & $x$ & 989 \\
\hline 1010 & $x$ & 1010 & $x$ & $\mathrm{x}$ \\
\hline 1043 & $x$ & $\mathrm{x}$ & $x$ & 1043 \\
\hline 1082 & $x$ & $\mathrm{x}$ & 1082 & $\mathrm{x}$ \\
\hline 1098 & $x$ & $x$ & $\mathrm{x}$ & 1098 \\
\hline 1100 & 1100 & $x$ & $x$ & $\mathrm{x}$ \\
\hline 1153 & $x$ & $x$ & $\mathrm{x}$ & 1153 \\
\hline 1199 & $x$ & $x$ & 1199 & $\mathrm{x}$ \\
\hline 1207 & $x$ & $\mathrm{x}$ & $x$ & 1207 \\
\hline 1219 & $x$ & 1219 & $x$ & $x$ \\
\hline
\end{tabular}




\begin{tabular}{|c|c|c|c|c|}
\hline Union & Arapisto & Flarken & $\begin{array}{l}\text { Raigast- } \\
\text { vere }\end{array}$ & Rouge \\
\hline 1262 & $\mathrm{x}$ & $\mathrm{x}$ & $\mathrm{x}$ & 1262 \\
\hline 1315 & $x$ & $x$ & 1315 & $x$ \\
\hline 1317 & $x$ & $x$ & $x$ & 1317 \\
\hline 1370 & 1370 & $x$ & $x$ & $x$ \\
\hline 1371 & $x$ & $x$ & $x$ & 1371 \\
\hline 1423 & $x$ & 1423 & $x$ & $\mathrm{x}$ \\
\hline 1426 & $x$ & $x$ & $x$ & 1426 \\
\hline 1431 & $x$ & $x$ & 1431 & $x$ \\
\hline 1481 & $x$ & $x$ & $x$ & 1481 \\
\hline 1535 & $x$ & $x$ & $x$ & 1535 \\
\hline 1547 & $x$ & $x$ & 1547 & $x$ \\
\hline 1590 & $x$ & $x$ & $x$ & 1590 \\
\hline 1621 & $x$ & 1621 & $x$ & $x$ \\
\hline 1639 & 1639 & $x$ & $x$ & $x$ \\
\hline 1645 & $x$ & $x$ & $x$ & 1645 \\
\hline 1663 & $x$ & $x$ & 1663 & $x$ \\
\hline 1699 & $x$ & $x$ & $x$ & 1699 \\
\hline 1754 & $x$ & $x$ & $x$ & 1754 \\
\hline 1798 & $x$ & $x$ & 1798 & $x$ \\
\hline 1808 & $x$ & $x$ & $x$ & 1808 \\
\hline 1814 & $x$ & 1814 & $x$ & $x$ \\
\hline 1863 & $x$ & $x$ & $x$ & 1863 \\
\hline 1905 & 1905 & $x$ & $x$ & $x$ \\
\hline 1918 & $x$ & $x$ & $x$ & 1918 \\
\hline 1952 & $x$ & $x$ & 1952 & $x$ \\
\hline 1972 & $x$ & $x$ & $x$ & 1972 \\
\hline 2002 & $x$ & 2002 & $x$ & $x$ \\
\hline 2027 & $x$ & $x$ & $x$ & 2027 \\
\hline 2082 & $x$ & $x$ & $x$ & 2082 \\
\hline 2107 & $x$ & $x$ & 2107 & $x$ \\
\hline 2136 & $x$ & $x$ & $x$ & 2136 \\
\hline 2169 & 2169 & $x$ & $x$ & $x$ \\
\hline 2184 & $x$ & 2184 & $x$ & $x$ \\
\hline 2191 & $x$ & $x$ & $x$ & 2191 \\
\hline 2246 & $x$ & $x$ & $x$ & 2246 \\
\hline 2261 & $x$ & $x$ & 2261 & $x$ \\
\hline 2300 & $x$ & $x$ & $x$ & 2300 \\
\hline 2355 & $x$ & $\mathrm{x}$ & $x$ & 2355 \\
\hline 2362 & $x$ & 2362 & $x$ & $x$ \\
\hline 2409 & $x$ & $x$ & $x$ & 2409 \\
\hline 2415 & $x$ & $x$ & 2415 & $x$ \\
\hline 2431 & 2431 & $x$ & $x$ & $x$ \\
\hline
\end{tabular}

\begin{tabular}{|c|c|c|c|c|}
\hline Union & Arapisto & Flarken & $\begin{array}{l}\text { Raigast- } \\
\text { vere }\end{array}$ & Rouge \\
\hline 2464 & $\mathrm{x}$ & $x$ & $x$ & 2464 \\
\hline 2519 & $x$ & $x$ & $x$ & 2519 \\
\hline 2534 & $x$ & 2534 & $x$ & $x$ \\
\hline 2570 & $x$ & $x$ & 2570 & $x$ \\
\hline 2573 & $x$ & $x$ & 0 & 2573 \\
\hline 2628 & $x$ & $x$ & $x$ & 2628 \\
\hline 2683 & $x$ & $x$ & $x$ & 2683 \\
\hline 2690 & 2690 & $x$ & $x$ & $x$ \\
\hline 2702 & $x$ & 2702 & $x$ & $x$ \\
\hline 2724 & $x$ & $x$ & 2724 & $x$ \\
\hline 2737 & $x$ & $x$ & $x$ & 2737 \\
\hline 2792 & $x$ & $x$ & $x$ & 2792 \\
\hline 2847 & $x$ & $x$ & $x$ & 2847 \\
\hline 2866 & $x$ & 2866 & $x$ & $x$ \\
\hline 2878 & $x$ & $x$ & 2878 & $x$ \\
\hline 2901 & $x$ & $x$ & $x$ & 2901 \\
\hline 2947 & 2947 & $x$ & $x$ & $x$ \\
\hline 2956 & $x$ & $x$ & $x$ & 2956 \\
\hline 3011 & $x$ & $x$ & $x$ & 3011 \\
\hline 3024 & $x$ & 3024 & $x$ & $x$ \\
\hline 3033 & $x$ & $x$ & 3033 & $x$ \\
\hline 3065 & $x$ & $x$ & $x$ & 3065 \\
\hline 3120 & $x$ & $x$ & $x$ & 3120 \\
\hline 3174 & $x$ & $x$ & $x$ & 3174 \\
\hline 3179 & $x$ & 3179 & $x$ & $x$ \\
\hline 3187 & $x$ & $\mathrm{x}$ & 3187 & $x$ \\
\hline 3201 & 3201 & $x$ & $x$ & $x$ \\
\hline 3229 & $x$ & $x$ & $x$ & 3229 \\
\hline 3284 & $x$ & $x$ & $x$ & 3284 \\
\hline 3310 & $x$ & $x$ & 3310 & $x$ \\
\hline 3328 & $x$ & 3328 & $x$ & $x$ \\
\hline 3338 & $x$ & $x$ & $x$ & 3338 \\
\hline 3393 & $x$ & $x$ & $x$ & 3393 \\
\hline 3403 & $x$ & $x$ & 3403 & $\mathrm{x}$ \\
\hline 3448 & $\mathrm{x}$ & $x$ & $x$ & 3448 \\
\hline 3453 & 3453 & $x$ & $x$ & $x$ \\
\hline 3474 & $x$ & 3474 & $x$ & $x$ \\
\hline 3496 & $x$ & $\mathrm{x}$ & 3496 & $\mathrm{x}$ \\
\hline 3502 & $x$ & $x$ & $x$ & 3502 \\
\hline 3557 & $x$ & $x$ & $x$ & 3557 \\
\hline 3589 & $x$ & $x$ & 3589 & $\mathrm{x}$ \\
\hline 3612 & $x$ & $x$ & $x$ & 3612 \\
\hline
\end{tabular}




\begin{tabular}{|c|c|c|c|c|}
\hline Union & Arapisto & Flarken & $\begin{array}{c}\text { Raigast- } \\
\text { vere }\end{array}$ & Rouge \\
\hline 3615 & $x$ & 3615 & $x$ & $x$ \\
\hline 3666 & $x$ & $x$ & $x$ & 3666 \\
\hline 3682 & $x$ & $x$ & 3682 & $\mathrm{x}$ \\
\hline 3702 & 3702 & $x$ & $x$ & $x$ \\
\hline 3721 & $x$ & $x$ & $x$ & 3721 \\
\hline 3752 & $x$ & 3752 & $x$ & $x$ \\
\hline 3774 & $x$ & $x$ & 3774 & $x$ \\
\hline 3775 & $x$ & $x$ & $x$ & 3775 \\
\hline 3830 & $x$ & $x$ & $x$ & 3830 \\
\hline 3867 & $x$ & $x$ & 3867 & $x$ \\
\hline 3885 & $x$ & $x$ & $x$ & 3885 \\
\hline 3886 & $x$ & 3886 & $x$ & $x$ \\
\hline 3939 & $x$ & $x$ & $x$ & 3939 \\
\hline 3948 & 3948 & $x$ & $x$ & $x$ \\
\hline 3960 & $x$ & $x$ & 3960 & $x$ \\
\hline 3994 & $x$ & $x$ & $x$ & 3994 \\
\hline 4015 & $x$ & 4015 & $x$ & $x$ \\
\hline 4049 & $x$ & $x$ & $x$ & 4049 \\
\hline 4053 & $x$ & $x$ & 4053 & $x$ \\
\hline 4103 & $x$ & $x$ & $x$ & 4103 \\
\hline 4140 & $x$ & 4140 & $x$ & $x$ \\
\hline 4146 & $x$ & $x$ & 4146 & $x$ \\
\hline 4158 & $x$ & $x$ & $x$ & 4158 \\
\hline 4191 & 4191 & $x$ & $x$ & $x$ \\
\hline 4213 & $x$ & $x$ & $x$ & 4213 \\
\hline 4232 & $x$ & $\mathrm{x}$ & 4232 & $x$ \\
\hline 4262 & $x$ & 4262 & $x$ & $x$ \\
\hline 4267 & $x$ & $x$ & $\mathrm{x}$ & 4267 \\
\hline 4313 & $x$ & $x$ & 4313 & $x$ \\
\hline 4322 & $x$ & $x$ & $x$ & 4322 \\
\hline 4376 & $x$ & $x$ & $x$ & 4376 \\
\hline 4380 & $x$ & 4380 & $x$ & $x$ \\
\hline 4393 & $x$ & $x$ & 4393 & $x$ \\
\hline 4431 & 4431 & $x$ & $x$ & 4431 \\
\hline 4473 & $x$ & $x$ & 4473 & $x$ \\
\hline 4486 & $x$ & $x$ & $x$ & 4486 \\
\hline 4495 & $x$ & 4495 & $x$ & $\mathrm{x}$ \\
\hline 4540 & $x$ & $x$ & $\mathrm{x}$ & 4540 \\
\hline 4553 & $x$ & $x$ & 4553 & $\mathrm{x}$ \\
\hline 4595 & $x$ & $x$ & $x$ & 4595 \\
\hline 4606 & $x$ & 4606 & $x$ & $x$ \\
\hline 4634 & $x$ & $x$ & 4634 & $x$ \\
\hline
\end{tabular}

\begin{tabular}{|c|c|c|c|c|}
\hline Union & Arapisto & Flarken & $\begin{array}{c}\text { Raigast- } \\
\text { vere }\end{array}$ & Rouge \\
\hline 4650 & $x$ & $x$ & $x$ & 4650 \\
\hline 4667 & 4667 & $x$ & $x$ & $x$ \\
\hline 4704 & $x$ & $x$ & $x$ & 4704 \\
\hline 4714 & $x$ & 4714 & 4714 & $x$ \\
\hline 4759 & $x$ & $x$ & $x$ & 4759 \\
\hline 4794 & $x$ & $x$ & 4794 & $x$ \\
\hline 4814 & $x$ & $x$ & $x$ & 4814 \\
\hline 4819 & $x$ & 4819 & $x$ & $x$ \\
\hline 4868 & $x$ & $x$ & $x$ & 4868 \\
\hline 4875 & $x$ & $x$ & 4875 & $x$ \\
\hline 4901 & 4901 & $x$ & $x$ & $x$ \\
\hline 4921 & $x$ & 4921 & $x$ & $x$ \\
\hline 4923 & $x$ & $x$ & $x$ & 4923 \\
\hline 4955 & $x$ & $x$ & 4955 & $x$ \\
\hline 4978 & $x$ & $x$ & $x$ & 4978 \\
\hline 5019 & $x$ & 5019 & $x$ & $x$ \\
\hline 5032 & $x$ & $x$ & $x$ & 5032 \\
\hline 5052 & $x$ & $x$ & 5052 & $x$ \\
\hline 5087 & $x$ & $x$ & $x$ & 5087 \\
\hline 5115 & $x$ & 5115 & $x$ & $x$ \\
\hline 5131 & 5131 & $x$ & $x$ & $x$ \\
\hline 5141 & $x$ & $x$ & $x$ & 5141 \\
\hline 5167 & $x$ & $x$ & 5167 & $x$ \\
\hline 5196 & $x$ & $x$ & $x$ & 5196 \\
\hline 5208 & $x$ & 5208 & $x$ & $x$ \\
\hline 5251 & $x$ & $x$ & $x$ & 5251 \\
\hline 5281 & $x$ & $x$ & 5281 & $x$ \\
\hline 5298 & $x$ & 5298 & $x$ & $x$ \\
\hline 5305 & $x$ & $x$ & $x$ & 5305 \\
\hline 5358 & 5358 & $x$ & $x$ & $x$ \\
\hline 5360 & $x$ & $x$ & $x$ & 5360 \\
\hline 5385 & $x$ & 5385 & $x$ & $x$ \\
\hline 5395 & $x$ & $x$ & 5395 & $x$ \\
\hline 5418 & $x$ & $x$ & $x$ & 5418 \\
\hline 5470 & $x$ & 5470 & $x$ & 5470 \\
\hline 5509 & $x$ & $x$ & 5509 & $x$ \\
\hline 5515 & $x$ & $x$ & $x$ & 5515 \\
\hline 5552 & $x$ & 5552 & $x$ & $\mathrm{x}$ \\
\hline 5570 & $x$ & $x$ & $x$ & 5570 \\
\hline 5581 & 5581 & $x$ & $x$ & $x$ \\
\hline 5620 & $x$ & $x$ & $x$ & 5620 \\
\hline 5624 & $x$ & $x$ & 5624 & $x$ \\
\hline
\end{tabular}




\begin{tabular}{|c|c|c|c|c|}
\hline Union & Arapisto & Flarken & $\begin{array}{c}\text { Raigast- } \\
\text { vere }\end{array}$ & Rouge \\
\hline 5632 & $x$ & 5632 & $\mathrm{x}$ & $x$ \\
\hline 5670 & $x$ & $x$ & $x$ & 5670 \\
\hline 5710 & $x$ & 5710 & $x$ & $x$ \\
\hline 5720 & $x$ & $x$ & $x$ & 5720 \\
\hline 5738 & $x$ & $x$ & 5738 & $x$ \\
\hline 5770 & $x$ & $x$ & $x$ & 5770 \\
\hline 5786 & $x$ & 5786 & $x$ & $x$ \\
\hline 5801 & 5801 & $x$ & $x$ & $x$ \\
\hline 5820 & $x$ & $x$ & $x$ & 5820 \\
\hline 5852 & $x$ & $x$ & 5852 & $x$ \\
\hline 5860 & $x$ & 5860 & $x$ & $x$ \\
\hline 5870 & $x$ & $x$ & $x$ & 5870 \\
\hline 5920 & $x$ & $\mathrm{x}$ & $x$ & 5920 \\
\hline 5931 & $x$ & 5931 & $x$ & $x$ \\
\hline 5965 & $x$ & $x$ & $x$ & 5965 \\
\hline 5967 & $x$ & $x$ & 5967 & $x$ \\
\hline 6001 & $x$ & 6001 & $x$ & $x$ \\
\hline 6015 & $x$ & $x$ & $x$ & 6015 \\
\hline 6017 & 6017 & $x$ & $x$ & $\mathrm{x}$ \\
\hline 6067 & $x$ & $x$ & $x$ & 6067 \\
\hline 6069 & $x$ & 6069 & $x$ & $x$ \\
\hline 6081 & $x$ & $x$ & 6081 & $x$ \\
\hline 6125 & $x$ & $x$ & $x$ & 6125 \\
\hline 6136 & $x$ & 6136 & $x$ & $x$ \\
\hline 6165 & $x$ & $x$ & $x$ & 6165 \\
\hline 6194 & $x$ & $x$ & 6194 & $x$ \\
\hline 6200 & $x$ & 6200 & $\mathrm{x}$ & $x$ \\
\hline 6219 & $x$ & $x$ & $x$ & 6219 \\
\hline 6229 & 6229 & $x$ & $x$ & $x$ \\
\hline 6264 & $x$ & 6264 & $x$ & $x$ \\
\hline 6270 & $x$ & $x$ & $\mathrm{x}$ & 6270 \\
\hline 6304 & $x$ & $x$ & 6304 & $x$ \\
\hline 6324 & $x$ & $x$ & $x$ & 6324 \\
\hline 6326 & $x$ & 6326 & $x$ & $x$ \\
\hline 6370 & $x$ & $x$ & $x$ & 6370 \\
\hline 6386 & $x$ & 6386 & $x$ & $x$ \\
\hline 6415 & $x$ & $x$ & 6415 & 6415 \\
\hline 6437 & 6437 & $x$ & $x$ & $x$ \\
\hline 6446 & $x$ & 6446 & $x$ & $x$ \\
\hline 6470 & $x$ & $x$ & $x$ & 6470 \\
\hline 6504 & $x$ & 6504 & $x$ & $\mathrm{x}$ \\
\hline 6516 & $x$ & $x$ & $x$ & 6516 \\
\hline
\end{tabular}

\begin{tabular}{|c|c|c|c|c|}
\hline Union & Arapisto & Flarken & $\begin{array}{c}\text { Raigast- } \\
\text { vere }\end{array}$ & Rouge \\
\hline 6526 & $x$ & $\mathrm{x}$ & 6526 & $x$ \\
\hline 6562 & $x$ & 6562 & $x$ & $x$ \\
\hline 6570 & $x$ & $x$ & $x$ & 6570 \\
\hline 6619 & $x$ & 6619 & $x$ & $x$ \\
\hline 6620 & $x$ & $x$ & $x$ & 6620 \\
\hline 6637 & $x$ & $x$ & 6637 & $x$ \\
\hline 6641 & 6641 & $x$ & $x$ & $x$ \\
\hline 6670 & $x$ & $x$ & $x$ & 6670 \\
\hline 6674 & $x$ & 6674 & $x$ & $x$ \\
\hline 6729 & $x$ & $x$ & $x$ & 6729 \\
\hline 6730 & $x$ & 6730 & $x$ & $x$ \\
\hline 6748 & $x$ & $x$ & 6748 & $x$ \\
\hline 6770 & $x$ & $x$ & $x$ & 6770 \\
\hline 6784 & $x$ & 6784 & $x$ & $x$ \\
\hline 6809 & $x$ & $x$ & $x$ & 6809 \\
\hline 6838 & $x$ & 6838 & $x$ & $x$ \\
\hline 6841 & 6841 & $x$ & $x$ & $x$ \\
\hline 6859 & $x$ & $x$ & 6859 & $x$ \\
\hline 6880 & $x$ & $\mathrm{x}$ & $x$ & 6880 \\
\hline 6892 & $x$ & 6892 & $x$ & $x$ \\
\hline 6920 & $x$ & $x$ & $x$ & 6920 \\
\hline 6945 & $x$ & 6945 & $x$ & $x$ \\
\hline 6970 & $x$ & $x$ & 6970 & 6970 \\
\hline 6998 & $x$ & 6998 & $x$ & $x$ \\
\hline 7012 & $x$ & $x$ & $x$ & 7012 \\
\hline 7037 & 7037 & $x$ & $x$ & $x$ \\
\hline 7040 & $x$ & $x$ & $x$ & 7040 \\
\hline 7051 & $x$ & 7051 & $x$ & $x$ \\
\hline 7067 & $x$ & $x$ & $x$ & 7067 \\
\hline 7081 & $x$ & $\mathrm{x}$ & 7081 & $x$ \\
\hline 7104 & $x$ & 7104 & $x$ & $x$ \\
\hline 7108 & $x$ & $x$ & $x$ & 7108 \\
\hline 7140 & $x$ & $\mathrm{x}$ & $x$ & 7140 \\
\hline 7157 & $x$ & 7157 & $x$ & $x$ \\
\hline 7170 & $x$ & $x$ & $x$ & 7170 \\
\hline 7192 & $x$ & $x$ & 7192 & $x$ \\
\hline 7198 & $x$ & $\mathrm{x}$ & $x$ & 7198 \\
\hline 7211 & $x$ & 7211 & $x$ & $x$ \\
\hline 7229 & 7229 & $x$ & $x$ & $\mathrm{x}$ \\
\hline 7235 & $x$ & $x$ & $x$ & 7235 \\
\hline 7264 & $x$ & 7264 & $x$ & $\mathrm{x}$ \\
\hline 7270 & $x$ & $x$ & $x$ & 7270 \\
\hline
\end{tabular}


A BAYESIAN SPATIO-TEMPORAL TEMPERATURE RECONSTRUCTION 21

\begin{tabular}{|c|c|c|c|c|}
\hline Union & Arapisto & Flarken & $\begin{array}{c}\text { Raigast- } \\
\text { vere }\end{array}$ & Rouge \\
\hline 7288 & $\mathrm{x}$ & $x$ & 7288 & $x$ \\
\hline 7318 & $x$ & 7318 & $x$ & $x$ \\
\hline 7320 & $x$ & $x$ & $x$ & 7320 \\
\hline 7370 & $x$ & $x$ & 7370 & $x$ \\
\hline 7373 & $x$ & 7373 & $x$ & $x$ \\
\hline 7400 & $x$ & $x$ & $x$ & 7400 \\
\hline 7416 & 7416 & $x$ & $x$ & $x$ \\
\hline 7428 & $x$ & 7428 & $x$ & $x$ \\
\hline 7451 & $x$ & $x$ & 7451 & $x$ \\
\hline 7453 & $x$ & $x$ & $x$ & 7453 \\
\hline 7484 & $x$ & 7484 & $x$ & $x$ \\
\hline 7498 & $x$ & $x$ & $x$ & 7498 \\
\hline 7540 & $x$ & 7540 & $x$ & $x$ \\
\hline 7550 & $x$ & $x$ & $x$ & 7550 \\
\hline 7597 & $x$ & 7597 & $x$ & $x$ \\
\hline 7599 & 7599 & $x$ & $x$ & $x$ \\
\hline 7600 & $x$ & $x$ & $x$ & 7600 \\
\hline 7615 & $x$ & $x$ & 7615 & $x$ \\
\hline 7650 & $x$ & $x$ & $x$ & 7650 \\
\hline 7656 & $x$ & 7656 & $x$ & $x$ \\
\hline 7696 & $x$ & $x$ & 7696 & $x$ \\
\hline 7700 & $x$ & $x$ & $x$ & 7700 \\
\hline 7715 & $x$ & 7715 & $x$ & $x$ \\
\hline 7724 & 7724 & $x$ & $x$ & $x$ \\
\hline 7742 & 7742 & $x$ & $x$ & $\mathrm{x}$ \\
\hline 7750 & $x$ & $x$ & $x$ & 7750 \\
\hline 7759 & 7759 & $x$ & $x$ & $x$ \\
\hline 7776 & $x$ & 7776 & $x$ & $x$ \\
\hline 7777 & 7777 & $x$ & $x$ & $x$ \\
\hline 7778 & $x$ & $x$ & 7778 & $x$ \\
\hline 7795 & 7795 & $x$ & $x$ & $x$ \\
\hline 7800 & $x$ & $x$ & $x$ & 7800 \\
\hline 7812 & 7812 & $x$ & $x$ & $x$ \\
\hline 7830 & 7830 & $\mathrm{x}$ & $x$ & $x$ \\
\hline 7838 & $x$ & 7838 & $x$ & $x$ \\
\hline 7847 & 7847 & $x$ & $x$ & $x$ \\
\hline 7850 & $x$ & $x$ & $\mathrm{x}$ & 7850 \\
\hline 7860 & $x$ & $x$ & 7860 & $x$ \\
\hline 7864 & 7864 & $x$ & $x$ & $x$ \\
\hline 7882 & 7882 & $x$ & $x$ & $x$ \\
\hline 7899 & 7899 & $x$ & $x$ & $x$ \\
\hline 7900 & $x$ & $x$ & $x$ & 7900 \\
\hline
\end{tabular}

\begin{tabular}{|c|c|c|c|c|}
\hline Union & Arapisto & Flarken & $\begin{array}{l}\text { Raigast- } \\
\text { vere }\end{array}$ & Rouge \\
\hline 7901 & $x$ & 7901 & $\mathrm{x}$ & $x$ \\
\hline 7916 & 7916 & $x$ & $x$ & $x$ \\
\hline 7933 & 7933 & $x$ & $x$ & $x$ \\
\hline 7942 & $x$ & $x$ & 7942 & $x$ \\
\hline 7950 & $x$ & $x$ & $x$ & 7950 \\
\hline 7951 & 7951 & $x$ & $x$ & $x$ \\
\hline 7965 & $x$ & 7965 & $x$ & $x$ \\
\hline 7968 & 7968 & $x$ & $x$ & $x$ \\
\hline 7985 & 7985 & $x$ & $x$ & $x$ \\
\hline 8000 & $x$ & $x$ & $x$ & 8000 \\
\hline 8002 & 8002 & $x$ & $x$ & $x$ \\
\hline 8019 & 8019 & $x$ & $x$ & $x$ \\
\hline 8023 & $x$ & $x$ & 8023 & $\mathrm{x}$ \\
\hline 8025 & $x$ & $x$ & $x$ & 8025 \\
\hline 8032 & $x$ & 8032 & $x$ & $x$ \\
\hline 8036 & 8036 & $x$ & $x$ & $x$ \\
\hline 8050 & $x$ & $x$ & $x$ & 8050 \\
\hline 8052 & 8052 & $x$ & $x$ & $x$ \\
\hline 8069 & 8069 & $x$ & $x$ & $\mathrm{x}$ \\
\hline 8075 & $x$ & $x$ & $x$ & 8075 \\
\hline 8086 & 8086 & $x$ & $x$ & $x$ \\
\hline 8090 & $x$ & $x$ & 8090 & $x$ \\
\hline 8099 & $x$ & 8099 & $x$ & $x$ \\
\hline 8100 & $x$ & $x$ & $x$ & 8100 \\
\hline 8103 & 8103 & $x$ & $x$ & $\mathrm{x}$ \\
\hline 8118 & $x$ & $x$ & $x$ & 8118 \\
\hline 8119 & 8119 & $x$ & $x$ & $x$ \\
\hline 8130 & $x$ & $x$ & $x$ & 8130 \\
\hline 8136 & 8136 & $x$ & $x$ & $x$ \\
\hline 8141 & $x$ & $x$ & 8141 & $x$ \\
\hline 8150 & $x$ & $x$ & $x$ & 8150 \\
\hline 8152 & 8152 & $x$ & $x$ & $x$ \\
\hline 8166 & $x$ & $x$ & $x$ & 8166 \\
\hline 8169 & 8169 & 8169 & $x$ & $\mathrm{x}$ \\
\hline 8183 & $x$ & $x$ & $x$ & 8183 \\
\hline 8185 & 8185 & $x$ & $x$ & $x$ \\
\hline 8193 & $x$ & $x$ & 8193 & $x$ \\
\hline 8200 & $x$ & $x$ & $x$ & 8200 \\
\hline 8202 & 8202 & $x$ & $x$ & $x$ \\
\hline 8217 & $x$ & $x$ & $x$ & 8217 \\
\hline 8218 & 8218 & $x$ & $x$ & $x$ \\
\hline 8234 & $x$ & $x$ & $x$ & 8234 \\
\hline
\end{tabular}




\begin{tabular}{|c|c|c|c|c|}
\hline Union & Arapisto & Flarken & $\begin{array}{l}\text { Raigast- } \\
\text { vere }\end{array}$ & Rouge \\
\hline 8235 & 8235 & $x$ & $x$ & $x$ \\
\hline 8241 & $x$ & 8241 & $x$ & $x$ \\
\hline 8244 & $x$ & $x$ & 8244 & $x$ \\
\hline 8250 & $x$ & $x$ & $x$ & 8250 \\
\hline 8251 & 8251 & $x$ & $x$ & $x$ \\
\hline 8267 & 8267 & $x$ & $x$ & $x$ \\
\hline 8275 & $x$ & $x$ & $x$ & 8275 \\
\hline 8283 & 8283 & $x$ & $\mathrm{x}$ & $x$ \\
\hline 8295 & $x$ & $x$ & 8295 & $x$ \\
\hline 8300 & $x$ & $x$ & $x$ & 8300 \\
\hline 8314 & $x$ & 8314 & $x$ & $x$ \\
\hline 8315 & 8315 & $\mathrm{x}$ & $x$ & $\mathrm{x}$ \\
\hline 8325 & $x$ & $x$ & $x$ & 8325 \\
\hline 8331 & 8331 & $x$ & $x$ & $x$ \\
\hline 8347 & 8347 & $x$ & 8347 & $x$ \\
\hline 8350 & $x$ & $x$ & $x$ & 8350 \\
\hline 8363 & 8363 & $x$ & $x$ & $x$ \\
\hline 8375 & $x$ & $x$ & $x$ & 8375 \\
\hline 8379 & 8379 & $x$ & $x$ & $x$ \\
\hline 8389 & $x$ & 8389 & $x$ & $x$ \\
\hline 8395 & 8395 & $x$ & $x$ & $x$ \\
\hline 8398 & $x$ & $x$ & 8398 & $x$ \\
\hline 8400 & $x$ & $x$ & $x$ & 8400 \\
\hline 8411 & 8411 & $x$ & $x$ & $x$ \\
\hline 8425 & $x$ & $x$ & $x$ & 8425 \\
\hline 8427 & 8427 & $x$ & $x$ & $x$ \\
\hline 8442 & 8442 & $x$ & $x$ & $x$ \\
\hline 8450 & $x$ & $x$ & 8450 & 8450 \\
\hline 8458 & 8458 & $x$ & $x$ & $x$ \\
\hline 8467 & $x$ & 8467 & $x$ & $x$ \\
\hline 8473 & 8473 & $x$ & $x$ & $x$ \\
\hline 8489 & 8489 & $x$ & $x$ & $x$ \\
\hline 8500 & $x$ & $x$ & $x$ & 8500 \\
\hline 8501 & $x$ & $x$ & 8501 & $x$ \\
\hline 8547 & $x$ & 8547 & $x$ & $x$ \\
\hline 8550 & $x$ & $x$ & $\mathrm{x}$ & 8550 \\
\hline 8552 & $x$ & $x$ & 8552 & $x$ \\
\hline 8596 & 8596 & $x$ & $x$ & $x$ \\
\hline 8600 & $x$ & $\mathrm{x}$ & $x$ & 8600 \\
\hline 8629 & $x$ & 8629 & $x$ & $x$ \\
\hline 8636 & $x$ & $x$ & 8636 & $x$ \\
\hline 8650 & $x$ & $x$ & $x$ & 8650 \\
\hline
\end{tabular}

\begin{tabular}{|c|c|c|c|c|}
\hline Union & Arapisto & Flarken & $\begin{array}{l}\text { Raigast- } \\
\text { vere }\end{array}$ & Rouge \\
\hline 8700 & $\mathrm{x}$ & $x$ & $x$ & 8700 \\
\hline 8713 & $x$ & 8713 & $x$ & $x$ \\
\hline 8745 & 8745 & $x$ & $x$ & $x$ \\
\hline 8750 & $\mathrm{x}$ & $x$ & $x$ & 8750 \\
\hline 8752 & $x$ & $x$ & 8752 & $x$ \\
\hline 8800 & $x$ & 8800 & $x$ & 8800 \\
\hline 8841 & $x$ & $\mathrm{x}$ & $x$ & 8841 \\
\hline 8868 & $x$ & $x$ & 8868 & $x$ \\
\hline 8889 & 8889 & $x$ & $x$ & $x$ \\
\hline 8890 & $x$ & 8890 & $x$ & $x$ \\
\hline 8900 & $x$ & $x$ & $x$ & 8900 \\
\hline 8948 & $x$ & $x$ & $x$ & 8948 \\
\hline 8983 & $x$ & 8983 & $x$ & $x$ \\
\hline 8984 & $x$ & $x$ & 8984 & $x$ \\
\hline 9002 & $x$ & $x$ & $x$ & 9002 \\
\hline 9027 & 9027 & $x$ & $x$ & $x$ \\
\hline 9050 & $x$ & $x$ & $x$ & 9050 \\
\hline 9078 & $x$ & 9078 & $x$ & $x$ \\
\hline 9100 & $x$ & $x$ & 9100 & 9100 \\
\hline 9148 & $x$ & $x$ & $x$ & 9148 \\
\hline 9160 & 9160 & $x$ & $x$ & $x$ \\
\hline 9176 & $x$ & 9176 & $x$ & $x$ \\
\hline 9200 & $x$ & $x$ & $x$ & 9200 \\
\hline 9216 & $x$ & $x$ & 9216 & $\mathrm{x}$ \\
\hline 9250 & $x$ & $x$ & $x$ & 9250 \\
\hline 9277 & $x$ & 9277 & $x$ & $x$ \\
\hline 9287 & 9287 & $x$ & $x$ & $x$ \\
\hline 9300 & $x$ & $x$ & $x$ & 9300 \\
\hline 9332 & $x$ & $x$ & 9332 & $x$ \\
\hline 9350 & $x$ & $\mathrm{x}$ & $x$ & 9350 \\
\hline 9381 & $x$ & 9381 & $x$ & $x$ \\
\hline 9400 & $x$ & $x$ & $x$ & 9400 \\
\hline 9409 & 9409 & $x$ & $\mathrm{x}$ & $x$ \\
\hline 9448 & $x$ & $x$ & 9448 & $x$ \\
\hline 9489 & $x$ & 9489 & $x$ & $x$ \\
\hline 9525 & 9525 & $\mathrm{x}$ & $\mathrm{x}$ & $x$ \\
\hline 9564 & $x$ & $x$ & 9564 & $x$ \\
\hline 9600 & $x$ & 9600 & $x$ & 9600 \\
\hline 9635 & 9635 & $\mathrm{x}$ & $\mathrm{x}$ & $x$ \\
\hline 9680 & $\mathrm{x}$ & $x$ & 9680 & $x$ \\
\hline 9714 & $x$ & 9714 & $x$ & $x$ \\
\hline 9739 & 9739 & $x$ & $x$ & $x$ \\
\hline
\end{tabular}




\begin{tabular}{|c|c|c|c|c|}
\hline Union & Arapisto & Flarken & $\begin{array}{c}\text { Raigast- } \\
\text { vere }\end{array}$ & Rouge \\
\hline 9796 & $x$ & $\mathrm{x}$ & 9796 & $x$ \\
\hline 9800 & $x$ & $x$ & $x$ & 9800 \\
\hline 9832 & $x$ & 9832 & $x$ & $x$ \\
\hline 9838 & 9838 & $x$ & $x$ & $x$ \\
\hline 9912 & $x$ & $x$ & 9912 & $x$ \\
\hline 9930 & 9930 & $x$ & $x$ & $x$ \\
\hline 9953 & $x$ & 9953 & $x$ & $x$ \\
\hline 10000 & $x$ & $x$ & $x$ & 10000 \\
\hline 10016 & 10016 & $x$ & $x$ & $x$ \\
\hline 10028 & $x$ & $x$ & 10028 & $x$ \\
\hline 10078 & $x$ & 10078 & $x$ & $x$ \\
\hline 10096 & 10096 & $x$ & $x$ & $x$ \\
\hline 10144 & $x$ & $x$ & 10144 & $x$ \\
\hline 10169 & 10169 & $x$ & $x$ & $x$ \\
\hline 10200 & $x$ & $\mathrm{x}$ & $x$ & 10200 \\
\hline 10207 & $x$ & 10207 & $x$ & $x$ \\
\hline 10236 & 10236 & $x$ & $x$ & $x$ \\
\hline 10260 & $x$ & $x$ & 10260 & $x$ \\
\hline 10261 & 10261 & $x$ & $x$ & $x$ \\
\hline 10300 & $x$ & $x$ & $x$ & 10300 \\
\hline 10340 & $x$ & 10340 & $x$ & $x$ \\
\hline 10375 & $x$ & $x$ & $x$ & 10375 \\
\hline 10376 & $x$ & $x$ & 10376 & $x$ \\
\hline 10425 & $x$ & $x$ & $x$ & 10425 \\
\hline 10475 & $x$ & $x$ & $x$ & 10475 \\
\hline 10476 & $x$ & 10476 & $x$ & $x$ \\
\hline 10492 & $x$ & $x$ & 10492 & $x$ \\
\hline 10525 & $x$ & $x$ & $x$ & 10525 \\
\hline 10575 & $x$ & $x$ & $x$ & 10575 \\
\hline 10617 & $x$ & 10617 & $x$ & $x$ \\
\hline 10625 & $x$ & $x$ & $x$ & 10625 \\
\hline 10643 & $x$ & $x$ & $x$ & 10643 \\
\hline 10724 & $x$ & $x$ & 10724 & $\mathrm{x}$ \\
\hline 10729 & $x$ & $x$ & $x$ & 10729 \\
\hline
\end{tabular}

\begin{tabular}{|c|c|c|c|c|}
\hline Union & Arapisto & Flarken & $\begin{array}{c}\text { Raigast- } \\
\text { vere }\end{array}$ & Rouge \\
\hline 10762 & $x$ & 10762 & $x$ & $x$ \\
\hline 10791 & 10791 & $\mathrm{x}$ & $x$ & $x$ \\
\hline 10825 & $x$ & $x$ & $x$ & 10825 \\
\hline 10840 & $x$ & $x$ & 10840 & $x$ \\
\hline 10852 & 10852 & $x$ & $x$ & $x$ \\
\hline 10875 & $x$ & $x$ & $x$ & 10875 \\
\hline 10911 & $x$ & 10911 & $x$ & $x$ \\
\hline 10922 & $x$ & $x$ & $x$ & 10922 \\
\hline 10956 & $x$ & $x$ & 10956 & $\mathrm{x}$ \\
\hline 11019 & $x$ & $x$ & $\mathrm{x}$ & 11019 \\
\hline 11065 & $x$ & 11065 & $\mathrm{x}$ & $x$ \\
\hline 11072 & $x$ & $\mathrm{x}$ & 11072 & $x$ \\
\hline 11128 & $x$ & $x$ & $\mathrm{x}$ & 11128 \\
\hline 11188 & $x$ & $x$ & 11188 & $x$ \\
\hline 11221 & $x$ & $x$ & $x$ & 11221 \\
\hline 11223 & $x$ & 11223 & $\mathrm{x}$ & $x$ \\
\hline 11246 & $x$ & $\mathrm{x}$ & 11246 & $x$ \\
\hline 11304 & $x$ & $x$ & 11304 & $x$ \\
\hline 11321 & $x$ & $x$ & $x$ & 11321 \\
\hline 11362 & $x$ & $\mathrm{x}$ & 11362 & $x$ \\
\hline 11386 & $x$ & 11386 & $x$ & $x$ \\
\hline 11420 & $x$ & $x$ & 11420 & $\mathrm{x}$ \\
\hline 11421 & $x$ & $x$ & $x$ & 11421 \\
\hline 11478 & $x$ & $x$ & 11478 & $\mathrm{x}$ \\
\hline 11521 & $x$ & $x$ & $\mathrm{x}$ & 11521 \\
\hline 11536 & $x$ & $x$ & 11536 & $x$ \\
\hline 11553 & $x$ & 11553 & $\mathrm{x}$ & $x$ \\
\hline 11594 & $x$ & $\mathrm{x}$ & 11594 & $x$ \\
\hline 11621 & $x$ & $x$ & $x$ & 11621 \\
\hline 11721 & $x$ & $x$ & $x$ & 11721 \\
\hline 11725 & $x$ & 11725 & $x$ & $\mathrm{x}$ \\
\hline 11821 & $x$ & $\mathrm{x}$ & $x$ & 11821 \\
\hline 11902 & $x$ & 11902 & $x$ & $x$ \\
\hline 12084 & $x$ & 12084 & $x$ & $x$ \\
\hline
\end{tabular}



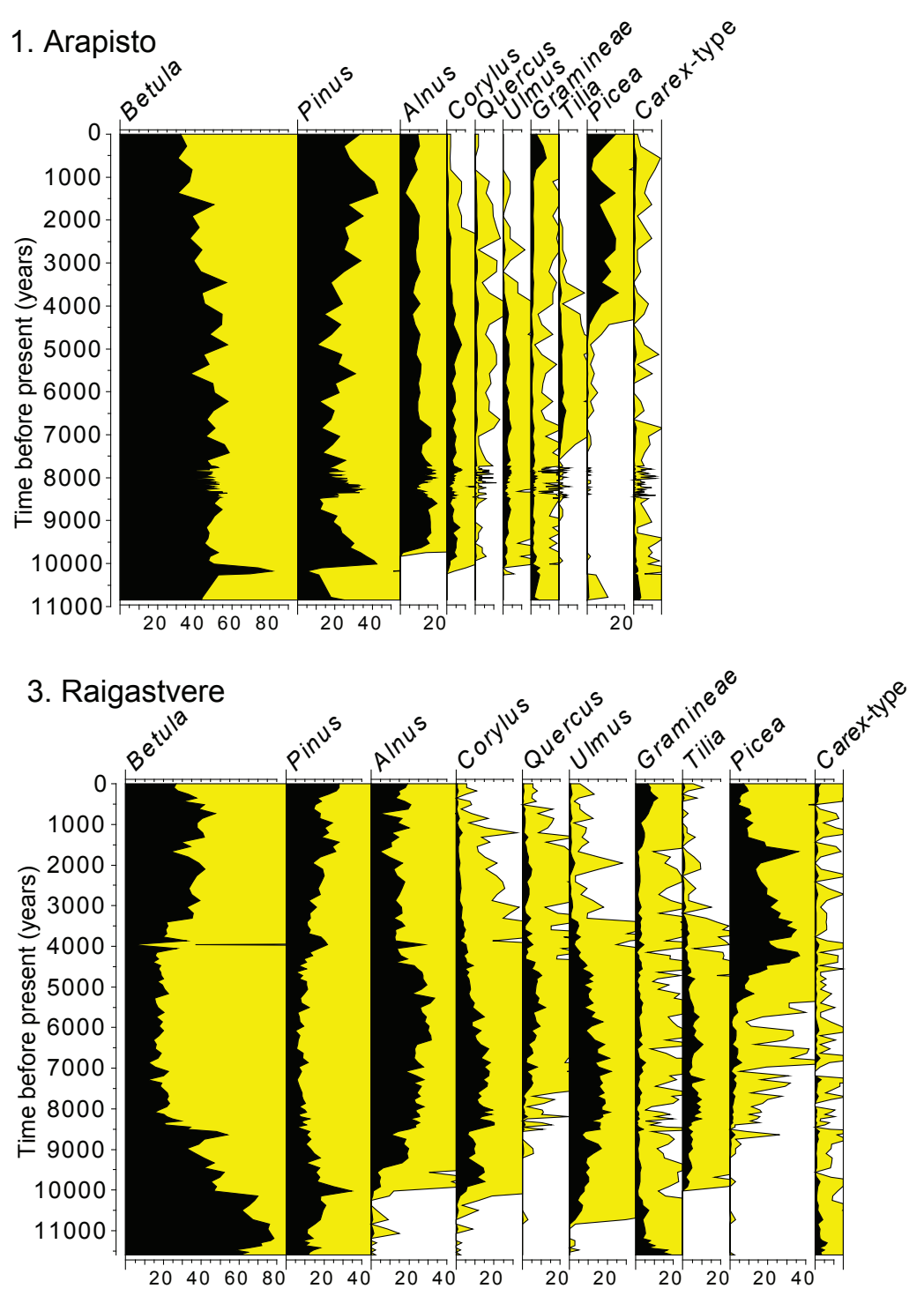
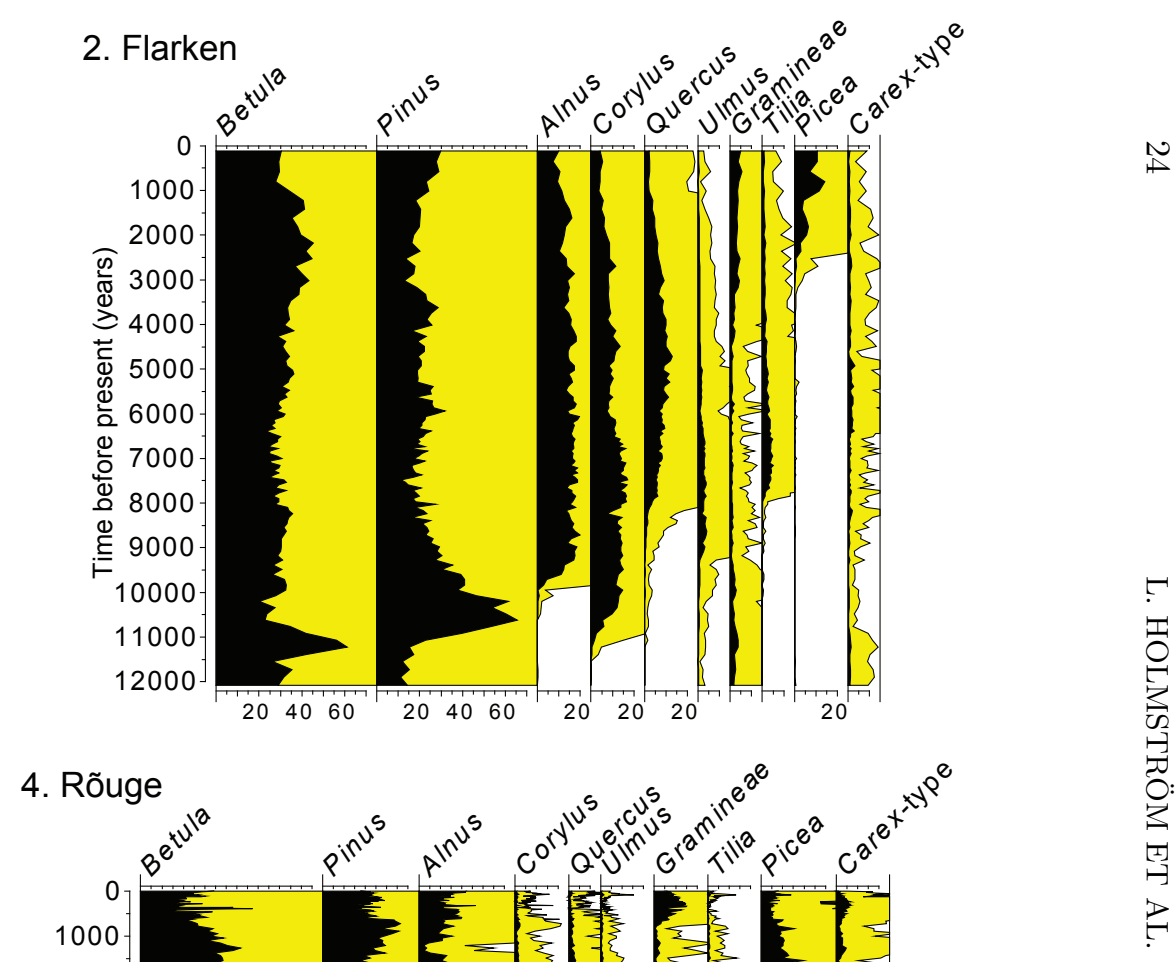

FiguRE S.13. Pollen diagrams from the four sites for which the temperature reconstructions were made. The diagrams were simplified by showing only the most common pollen types. The black silhouette shows the percentage value of each taxon and the yellow silhouette its 10-fold multiple of abundance. 